\title{
Reciprocal Changes in miRNA Expression with Pigmentation and Decreased Proliferation Induced in Mouse B16F1 Melanoma Cells by L-Tyrosine and 5-Bromo-2'-Deoxyuridine
}

\author{
Hernán Mauricio Rivera ${ }^{1,2} \mathbb{D}$, Esther Natalia Muñoz ${ }^{1,2}$, Daniel Osuna ${ }^{3}$, Mauro Florez ${ }^{3}$, Michael Carvajal ${ }^{3}$ \\ and Luis Alberto Gómez 2,4,* \\ 1 Department of Medicine, Universidad Nacional de Colombia, Bogotá 111321, Colombia; \\ hmriverae@unal.edu.co (H.M.R.); enmunozro@unal.edu.co (E.N.M.) \\ 2 Molecular Physiology Group, Sub-Direction of Scientific and Technological Research, Direction of Public \\ Health Research, National Institute of Health, Bogotá 111321, Colombia \\ 3 Science Department, Universidad Nacional de Colombia, Bogotá 111321, Colombia; \\ daosunag@unal.edu.co (D.O.); maeflorezro@unal.edu.co (M.F.); mscarvajalp@unal.edu.co (M.C.) \\ 4 Department of Physiological Sciences, Faculty of Medicine, Universidad Nacional de Colombia, \\ Bogotá 111321, Colombia \\ * Correspondence: lgomez@ins.gov.co
}

Citation: Rivera, H.M.; Muñoz, E.N.; Osuna, D.; Florez, M.; Carvajal, M.; Gómez, L.A. Reciprocal Changes in miRNA Expression with Pigmentation and Decreased Proliferation Induced in Mouse B16F1 Melanoma Cells by L-Tyrosine and 5-Bromo-2'-Deoxyuridine. Int. J. Mol. Sci. 2021, 22, 1591. https://doi.org/ 10.3390/ijms22041591

Received: 1 December 2020

Accepted: 3 January 2021

Published: 5 February 2021

Publisher's Note: MDPI stays neutral with regard to jurisdictional claims in published maps and institutional affiliations.

Copyright: (c) 2021 by the authors. Licensee MDPI, Basel, Switzerland. This article is an open access article distributed under the terms and conditions of the Creative Commons Attribution (CC BY) license (https:// creativecommons.org/licenses/by/ $4.0 /)$.
Abstract: Background: Many microRNAs have been identified as critical mediators in the progression of melanoma through its regulation of genes involved in different cellular processes such as melanogenesis, cell cycle control, and senescence. However, microRNAs' concurrent participation in syngeneic mouse B16F1 melanoma cells simultaneously induced decreased proliferation and differential pigmentation by exposure to 5-Brd-2'-dU (5'Bromo-2-deoxyuridine) and L-Tyr (L-Tyrosine) respectively, is poorly understood. Aim: To evaluate changes in the expression of microRNAs and identify which miRNAs in-network may contribute to the functional bases of phenotypes of differential pigmentation and reduction of proliferation in B16F1 melanoma cells exposed to 5-Brd-2'-dU and L-Tyr. Methods: Small RNAseq evaluation of the expression profiles of miRNAs in B16F1 melanoma cells exposed to 5 -Brd-2'-dU $(2.5 \mu \mathrm{g} / \mathrm{mL})$ and L-Tyr $(5 \mathrm{mM})$, as well as the expression by qRT-PCR of some molecular targets related to melanogenesis, cell cycle, and senescence. By bioinformatic analysis, we constructed network models of regulation and co-expression of microRNAs. Results: We confirmed that stimulation or repression of melanogenesis with L-Tyr or 5-Brd-2'-dU, respectively, generated changes in melanin concentration, reduction in proliferation, and changes in expression of microRNAs 470-3p, 470-5p, 30d-5p, 129-5p, 148b-3p, 27b-3p, and 211-5p, which presented patterns of coordinated and reciprocal co-expression, related to changes in melanogenesis through their putative targets Mitf, Tyr and Tyrp1, and control of cell cycle and senescence: Cyclin D1,Cdk2, Cdk4, p21, and p27. Conclusions: These findings provide insights into the molecular biology of melanoma of the way miRNAs are coordinated and reciprocal expression that may operate in a network as molecular bases for understanding changes in pigmentation and decreased proliferation induced in B16F1 melanoma cells exposed to L-Tyr and 5-Brd-2'-dU.

Keywords: melanoma; miRNAs; L-tyrosine; 5-bromo-2'-deoxyuridine; melanin; senescence; pigmentation

\section{Introduction}

Many transcripts show hundreds of genes change in expression in melanoma progression. These changes involve genetic and epigenetic mechanisms, such as mutations, gene silencing of tumor suppressors through DNA methylation in promoter regions, oncogene activation, chromatin remodeling, and regulation mediated by non-coding RNAs, such as microRNAs (miRNAs) through their regulation of genes involved in different cellular 
processes such as proliferation, death, cycle control, senescence, angiogenesis, differentiation, and even metastasis [1-8]. miRNA can have hundreds of mRNAs as molecular targets. One mRNA can target several miRNAs, and the researchers will identify variations in the expression of thousands of genes that may result from changes in some miRNAs' expression patterns [9-13].

Previous works on the mouse melanoma B16F1 cell line showed that 72-h exposure to $5 \mathrm{mM}$ L-Tyr resulted in increased cell size and pigmentation, while exposure to 5-Brd-2' $-\mathrm{dU}$ $2.5 \mu \mathrm{g} / \mathrm{mL}$ showed cells with a senescence-associated phenotype and hypopigmentation; however, a decrease in cell growth was reported $[14,15]$. These changes coincide with the differential expression of hundreds of genes evaluated in this experimental model, including cyclins, cyclin-dependent kinases (CDKs), and CDKs inhibitors [16,17]. In 2008, it was possible to identify two miRNAs (miR-138-5p and miR-470-3p) that presented differential expression, which had cyclin D1 as a molecular target [18]. However, the differential expression profile of miRNAs for this experimental model is unknown, as well as their possible coordinated and altered expression, evidence that could to expand our knowledge about melanoma plasticity is seen from the microRNAs post-transcriptional regulation mechanisms, and at least in part, to explain the changes in gene expression previously reported for this model of proliferation reduction and differential pigmentation.

Our objective was to assess miRNA expression changes and examine whether a coordinated expression of miRNAs and their potential targets are associated with the differential pigmentation and reduction of proliferation in B16F1 melanoma cells exposed to 5-Brd-2'-dU and L-Tyr. This work contributes to the knowledge about specific microRNA profiles in B16 melanoma cells under growth suppression and differential pigmentation. L-Tyr and 5-Brd-2'-dU induced coordinated expression on potential molecular targets and enhance the hypothesis of microRNAs that affect cellular programs by exerting control over different genes.

\section{Results}

\subsection{Decreased Proliferation and Pigmentation Changes in Melanoma B16F1 Cells}

The MTT assay and the exclusion of Trypan Blue revealed a reduction in cell B16F1 melanoma cells. Decrease in viable cells (to less than 50\%) secondary to $72 \mathrm{~h}$-long treatment with $5.0 \mathrm{mM}$ amino acid L-Tyrosine (L-Tyr) $(n=3)$ or $2.5 \mu \mathrm{g} / \mathrm{mL}$ thymidine analog 5Bromo-2' deoxyuridine (5-Brd-2'-dU) $(n=3)$; in both cases, exposure for $72 \mathrm{~h}$ to L-Tyr and 5 -Brd-2'-dU generated a statistically significant decrease in the number of B16F1 cells, from $3.6 \times 10^{6} \pm 1.16 \times 10^{5}$ to $7.4 \times 10^{5} \pm 9.23 \times 10^{4}\left(79 \%\right.$ reduction) and $1.3 \times 10^{6} \pm 5.5 \times 10^{4}$ (64\% reduction), respectively (Figure 1b; Figure S1c). Cells exposed to 5-Brd-2'-dU showed more expanded and flattened forms, while cells exposed to L-Tyr presented morphology similar to that of melanocytes with the presence of longer dendritic processes (Figure 1a). We observed these changes over time (240 h) (Figure S1a). Morphological changes and cell proliferation changes had already been reported previously for exposure to L-Tyr [19,20] and 5-Brd-2'-dU [21,22], although there were variations in exposure concentrations.

Reduction in cell number was associated with death. The number of cells in supernatants by I.P. incorporation; in unexposed cells (Control), the value was $1.1 \times 10^{4} \pm 1.1 \times 10^{3}$, while for L-Tyr exposure, it was $2.9 \times 10^{4} \pm 4.8 \times 10^{3}$. For 5 -Brd-2' $-d U$, it was $5.1 \times 10^{4} \pm 1.1 \times 10^{4}$. The values obtained in supernatants were on average $(97 \mathrm{X})$ and $(45 \mathrm{X})$ lower than the differences found by trypan blue in unexposed B16F1 cells (Control) and its counterpart, cells exposed to L-Tyr and 5-Brd-2'-dU. The above suggests that other mechanisms may explain the reduction of cells; therefore, we calculated the population doubling times from the MTT reductase activity assay and its corresponding calibration curve (Figure 1d; Figure S1b,c). The population doubling times increased from $19.6 \pm 3.94 \mathrm{~h}(\mathrm{CV}$, coefficient of variation of $20 \%$ ) to $48.67 \pm 6.25 \mathrm{~h}(\mathrm{CV}$ of $13 \%)$ and $27.03 \pm 3.0 \mathrm{~h}$ (CV of $11 \%$ ) for exposure to L-Tyr and 5-Brd-2'-dU, respectively. These differences indicated that reducing the number of cells at $72 \mathrm{~h}$ would be the consequence of variations in the cell cycle control. 

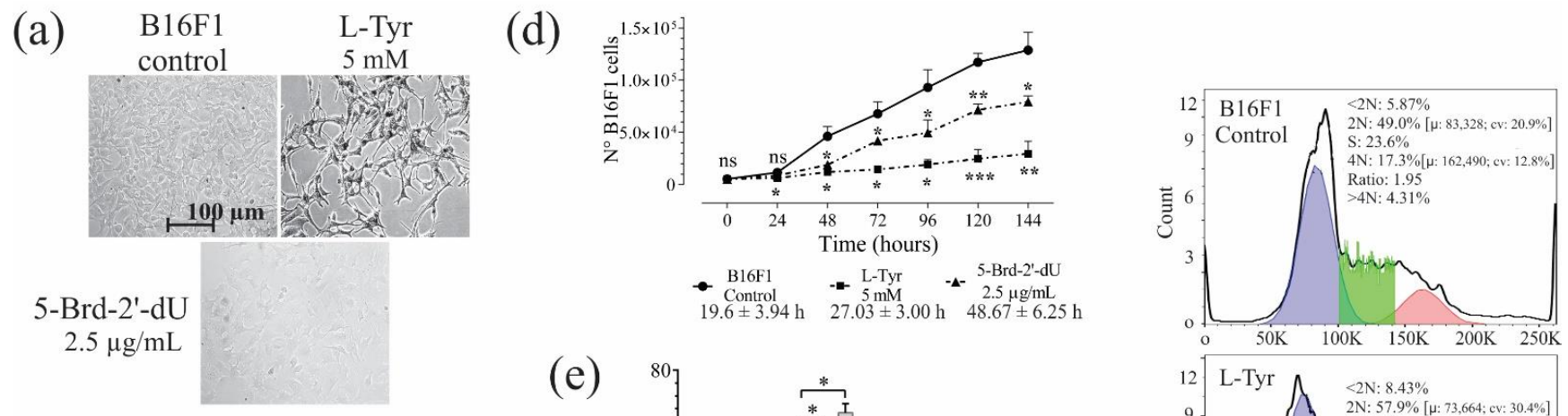

(e)

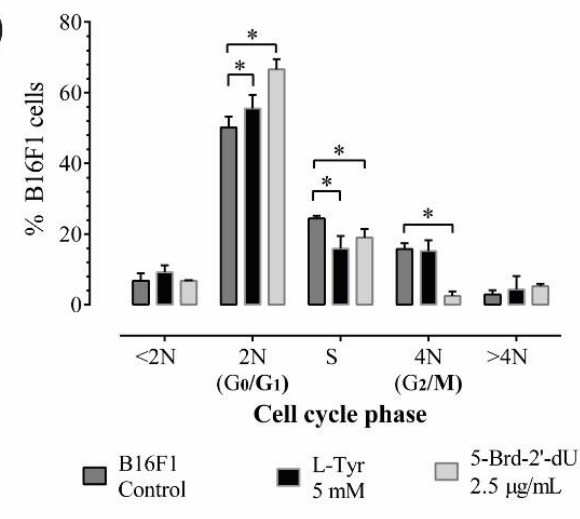

(c)
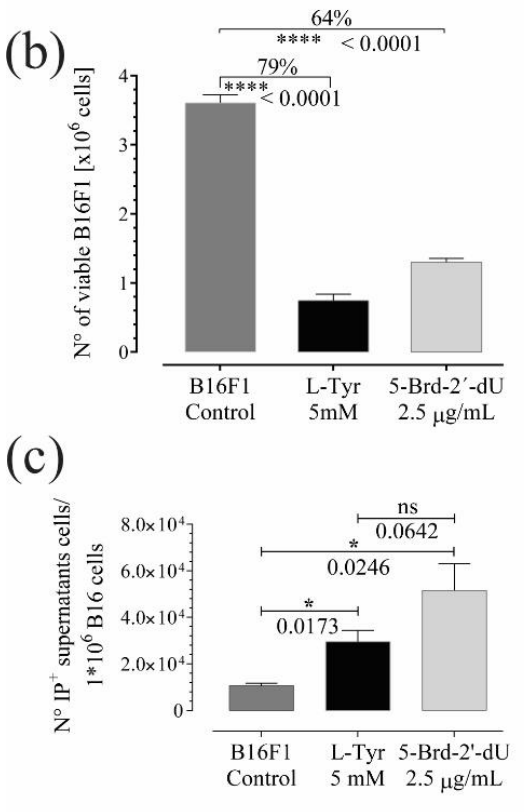

(f)

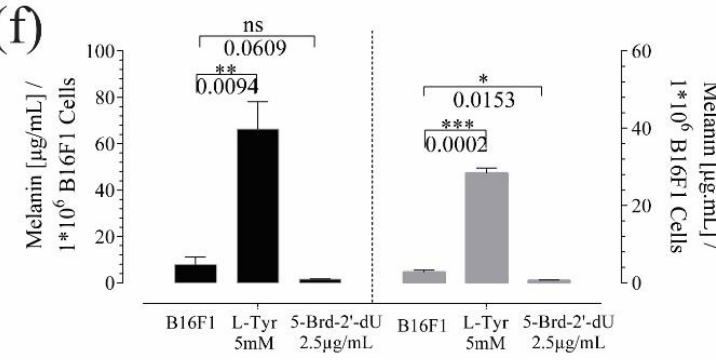

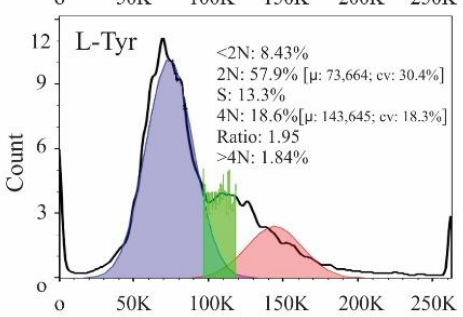

$15-5$-Brd-2'-dU $2 \mathrm{~N} \cdot 6.56 \%$
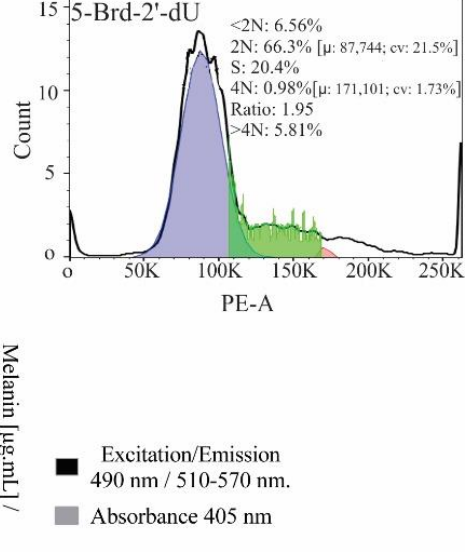

Figure 1. Exposure to L-Tyr or 5-Brd-2'-dU for $72 \mathrm{~h}$ in B16F1 cells generates a reduction in the number of cells and affects melanin concentration. (a) Representative photographs of B16F1 cells exposed to $5 \mathrm{mM}$ L-Tyr or $2.5 \mu \mathrm{g} / \mathrm{mL} 5-\mathrm{Brd}-2^{\prime}$-dU after 72 h. (b) Quantification of the number of viable cells by Trypan Blue exclusion assay. (c) The number of cells in supernatants that incorporate Propidium Iodide (I.P.). (d) Changes in B16F1 cell number by MTT assay and population doubling times. (e) Frequency histograms of DNA content. Permeable cells incorporated PI; the cell cycle analysis corresponds to a univariate Gaussian distribution model. FlowJo algorithm function revealed phase S cells, (f) Melanin concentration from B16F1 cells after exposure to L-Tyr or 5-Brd-2'-dU by spectrophotometry fluorescence. The significance $\left.{ }^{*}\right)$ using two-tailed multiple $t$-tests, and the differences were considered statistically significant for a $p$-value $<0.05$ using Welch's correction. significant $\left({ }^{*}\right)$ with $p<0.05$, very significant $\left({ }^{* *}\right)$ with $p<0.01$, highly significant $\left({ }^{* * *}\right)$ with $p<0.001$ and very highly significant $\left({ }^{* * * *}\right)$ with $p<0.0001$.

Cell cycle analysis (Figure 1e) showed changes in the DNA content of cells exposed to L-Tyr and 5-Brd-2'-dU. Indeed; statistically, significant changes occurred in the transition of the G0/G1 phase (from $50 \pm 3.0 \%$ to $66.6 \pm 2.8 \%$ ) and $\mathrm{G} 2 / \mathrm{M}$ (from $15.7 \pm 1.6 \%$ to $2.4 \pm 1.2 \%$ ) for 5-Brd-2'-dU and in the S phase for L-Tyr (from $24.4 \pm 0.7 \%$ to $15.8 \pm 3.6 \%$ ). The cells exposed to L-Tyr significantly increased in the G0/G1 phase $(55.5 \pm 3.8 \%, n=3)$.

Based on the method described $[23,24]$, we quantified the formation of melanin pigment in culture B16F1 melanoma cells under standardized conditions $[15,25]$ and 5-Brd$2^{\prime}$-dU $[14,21,26]$. Synthetic melanin helped construct calibration curves to quantify by spectrophotometry and fluorometry (Figure S1d). The quantification of melanin by both methods was comparable (Figure 1b) (Pearson's correlation coefficient 0.999). The two approaches allowed the detection of increase $(9 X)$ and decrease $(5 X)$ in melanin concentration in B16 cells exposed to L-Tyr and 5-Brd-2'-dU, respectively (Figure 1f). However, 
fluorometry was more sensitive (detection limit $0.098 \mu \mathrm{g} / \mathrm{mL}$ and $\mathrm{CV}$ of $9.85 \%$ ). Up to this point, the pooled results confirmed that exposure to L-Tyr and 5-Brd-2'-dU induces an arrest at different points in the cell cycle control for B16F1 cells and differential pigmentation phenotype that could be associated with changes in the expression of genes involved in melanin synthesis.

\subsection{Induction of Replicative Senescence in B16F1 Cells Exposed to 5-Brd-2'-dU}

5-Brd-2'-dU induced replicative senescence, a phenotype described in different cell models [27-29], including B16 cells [30,31]. We confirmed by Senescence-associated betagalactosidase (S.A. $\beta-\mathrm{Gal}$ ) assay, histone H3K9me3 labeling, apparent cell area measurement and flow cytometry, size analysis (FSC), and complexity (SSC) (Figure 2). Although not all cells were positive at $\mathrm{pH} 6.0$ (Figure 2a), the chromogenic S.A. $\beta$-Gal assay revealed a significant increase $(3.7 \mathrm{X})$ in the number of cells positive to the substrate $X-G a l$ by exposure to 5-Brd-2'-dU against control or those exposed to L-Tyr (Figure 2b).

The histone H3K9me3 associated with heterochromatin's remodeling $([31,32]$ increased in cells exposed to 5-Brd-2'-dU revealed by higher fluorescence intensity. The number of concentrated foci, which is associated with heterochromatin (SAHF) [32], some of these SAHF, coincides with a greater density obtained by DAPI labeling (Figure 2c).

Although the cells exposed to both stimuli showed greater apparent cell area $\left(2.6 \times 10^{-2} \mathrm{~mm}^{2}\right.$ for L-Tyr and $3.3 \times 10^{-2} \mathrm{~mm}^{2}$ for 5 -Brd-2'-dU) compared to the control $\left(1.5 \times 10^{-2} \mathrm{~mm}^{2}\right)$ (Figure $2 \mathrm{~d}$ ); cells with 5-Brd-2'-dU changed in size (FSC, quadrant Q3) going from 3.8\% to $9.7 \%$. These cells also had higher metabolic activity measured by MTT reductase assay (Figure S1d), where the slope of the calibration curve was 1.39 compared to 1.22 for the control. Overall, the results of exposure to 5-Brd-2'-dU suggest a phenotype associated with senescence and agree with that previously reported in 5-Brd-2' dU-induced senescence models, where an increase in lysosomal organelles would explain the more significant S.A. $\beta$-Gal activity and increase in messenger RNA [33-35]. Exposure to L-Tyr, the cells increased both in complexity (SSC) and in size (quadrants Q1 and Q2), going from 5.4 and $3.3 \%$ in the control cells to 26.7 and $20.8 \%$, respectively (Figure 2e).

\subsection{Small RNAseq and Differential Expression Analysis of miRNAs}

The alteration of different cellular programs in melanoma, control of the cell cycle, pigmentation, and senescence are associated with changes in the expression of miRNAs and their effect on the post-transcriptional regulation of target genes [11,36]. For the phenotypes induced in B16F1 cells, exposure to L-Tyr or 5-Brd-2'-dU causes changes in hundreds of genes $[14,31,37]$. However, it is unknown whether there are differences in the expression of miRNAs in these phenotypes. For this reason, we proceeded to identify and quantify by small RNAseq the expression of miRNAs in cells exposed to 5-Brd-2'-dU and L-Tyr (Figure S2) and establish the differences in expression concerning non-exposed cells (Figure 3).

The quality and integrity number (RIN) of the extracted RNA was within the values required for the Small RNAseq (Figure S2a). The average of readings obtained after sequencing for each experimental group $(n=3)$ was $1.38 \times 10^{7}, 8.0 \times 10^{6}$, and $1.03 \times 10^{7}$ for control cells, exposed to L-Tyr or 5-Brd-2'-dU, respectively (Figure S2b); these readings presented Phred score values close to 40 , indicating a $99.99 \%$ precision in the database call (data not shown, obtained by FastQC). With the readings, we constructed an expression matrix that contained in each row the identification number (I.D.) of the mature miRNA for sequences that presented $100 \%$ agreement with the sequences reported in miRBase version 21 . We listed on each column the total number of counts for each miRNA. The principal component analysis (PCA) showed greater homogeneity in the control samples and a more significant variation in those exposed to 5-Brd-2'-dU. When running DESEq2 on the expression matrix's normalized data, some miRNAs changed, measured as the $\log _{2}$ Fold Change, which suggests differential expression (M.A. plot of Figure S2d,e), some of them, when correcting multiple tests, maintained their statistical significance (Table 1). 
In cells exposed to L-Tyr, 35, 21 were under-expressed, and 14 over-expressed. In cells exposed to 5-Brd-2'-dU, the number of miRNAs with differential expression was 32, 11 of them under-expressed, and 21 over-expressed, all concerning control B16F1 cells (Table 1).

\section{(a)}

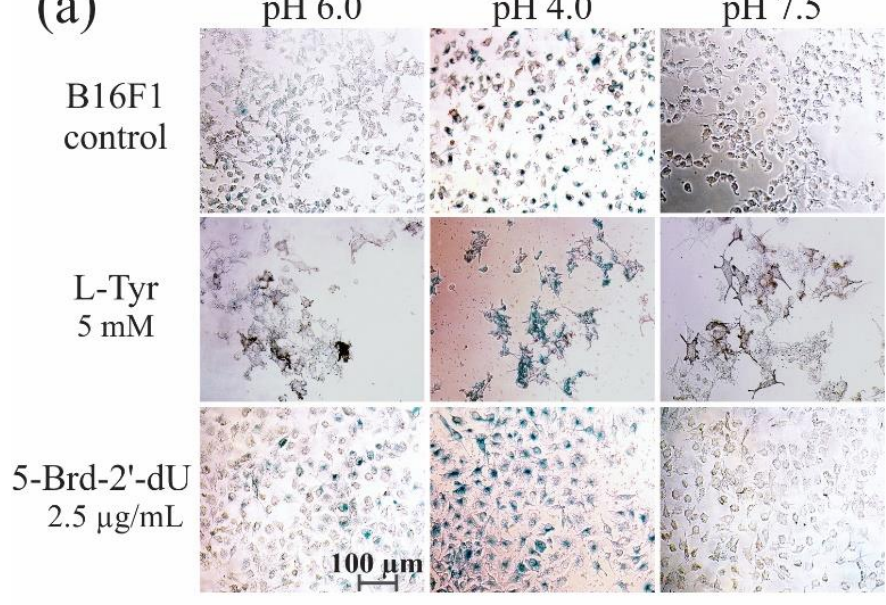

(c)

\section{B16F1 control}

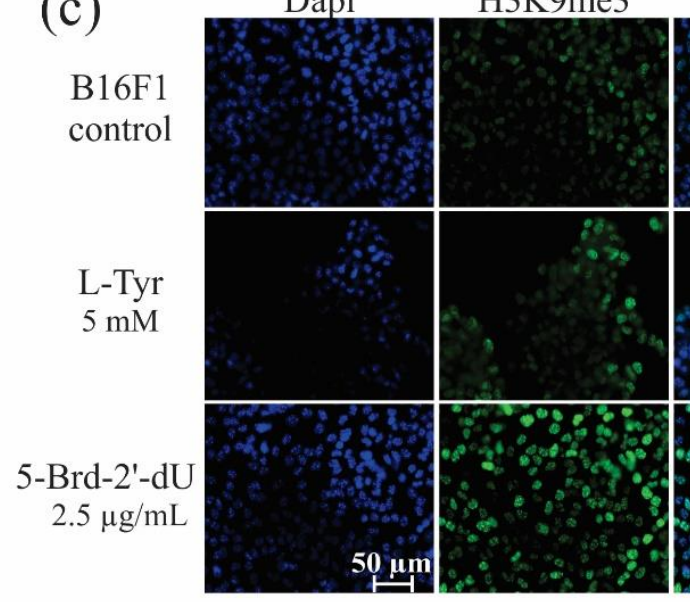

Dapi (b)

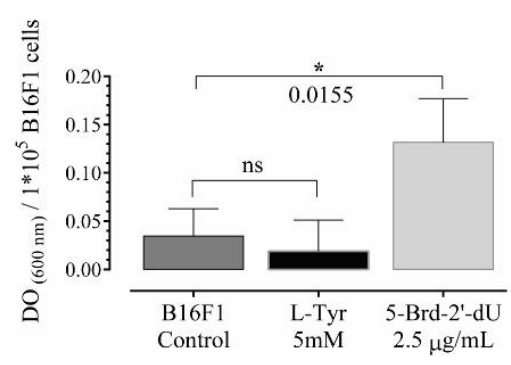

(d)

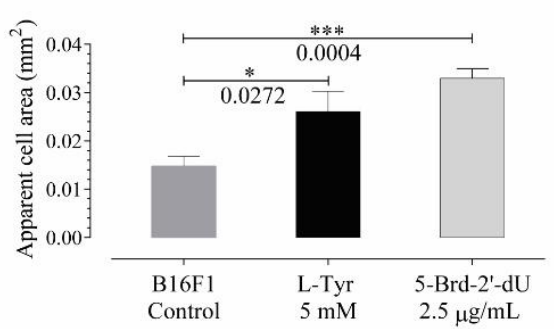

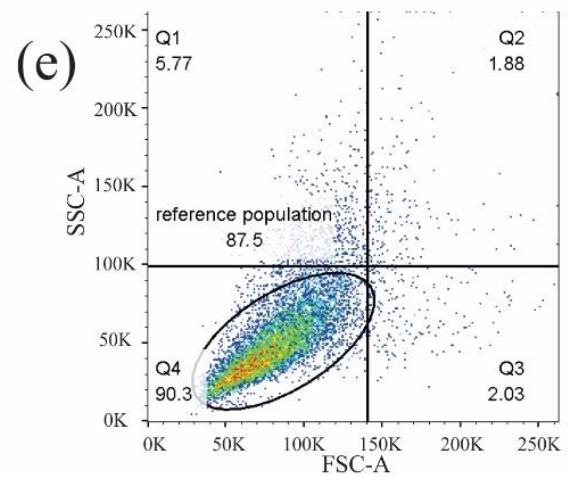

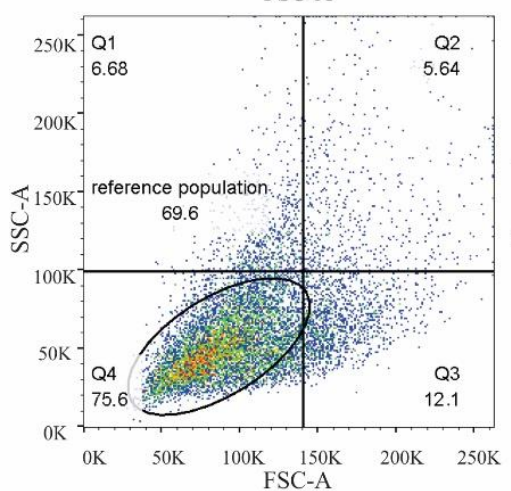

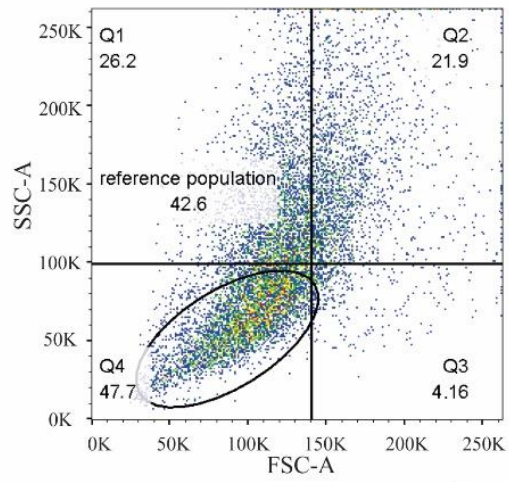

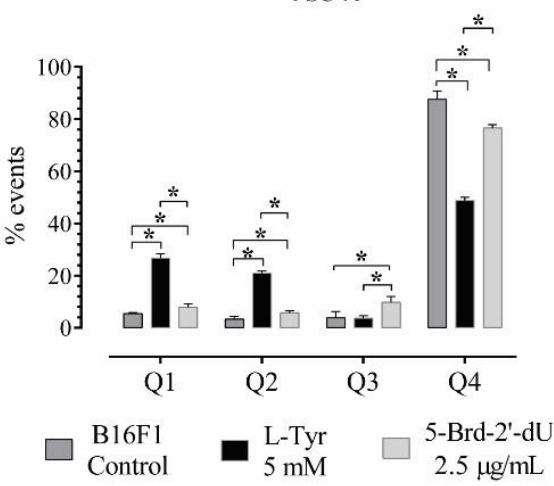

Figure 2. B16F1 cells exposed for $72 \mathrm{~h}$ to 5-Brd-2'-dU reveal changes in markers associated with senescence. (a) Representative photographs of B16F1 cells after the chromogenic assay for senescence-associated $\beta$-Galactosidase activity (S.A. $\beta$-Gal). (b) Quantification by spectrophotometry of the S.A. $\beta$-Gal activity at $\mathrm{pH}$ 6.0. (c) Representative photographs of immunofluorescence (IF) in B16F1 cells labeled against histone H3K9me3 (green) and nucleus staining with DAPI (blue). (d) Measurement of the apparent cell area in $\mu \mathrm{m} 2$ from bright-field photographs of $100 \mathrm{~B} 16 \mathrm{~F} 1$ cells $(n=3)$. (e) Diagram of cell complexity (SSC-A) and size (FSC-A) acquired by flow cytometry and its distribution by quartiles (Q1, Q2, Q3, and Q4). The significance level $\left.{ }^{*}\right)$ using two-tailed multiple $t$-tests, and the differences were considered statistically significant for a $p$-value $<0.05$ using the Holm-Sidak method. Significant $\left(^{*}\right)$ with $p<0.05$, significant $\left(^{* * *}\right)$ with $p<0.001$. 
(a)

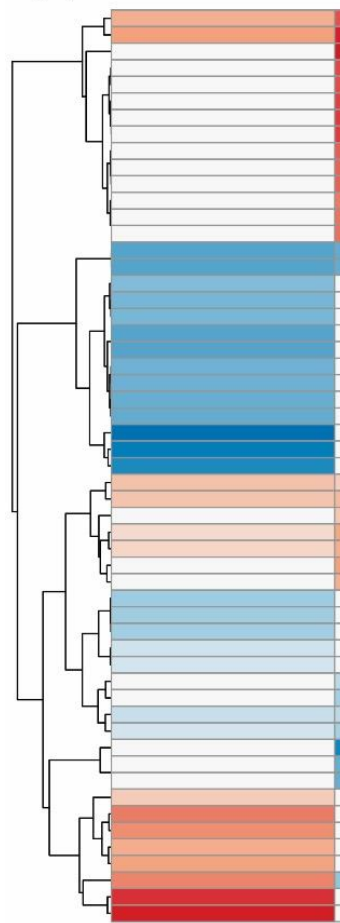

L-Tyr

(d)

$$
\begin{array}{r}
\text { Axon guidance } 3.86 \%- \\
\text { Wnt signaling pathway } 4.15 \% \\
\text { Ubiquitin mediated proteolysis } 4.15 \% \\
\text { Phospholinase D signaling pathway } 4.15 \% \\
\text { Cignaling pathways pluripotency of SC } 4.15 \% \\
\text { Cell cycle } 3.86 \% \\
\text { Proteoglycans in cyancer } 5.64 \% \\
\text { Cytokine-cytokine receptor interaction } 6.82 \% \\
\text { Glutamatergic synapse } 4.15 \% \\
\text { Jak-STAT signaling pathway } 5.34 \% \\
\text { MicroRNAs in cancer } 7.72 \% \\
\text { TGF-beta signaling pathway } 3.86 \%- \\
\text { mTOR signaling pathway } 3.26 \% \\
\text { FoxO signaling pathway } 6.23 \% \\
\text { Pathways in cancer } 12.46 \%
\end{array}
$$
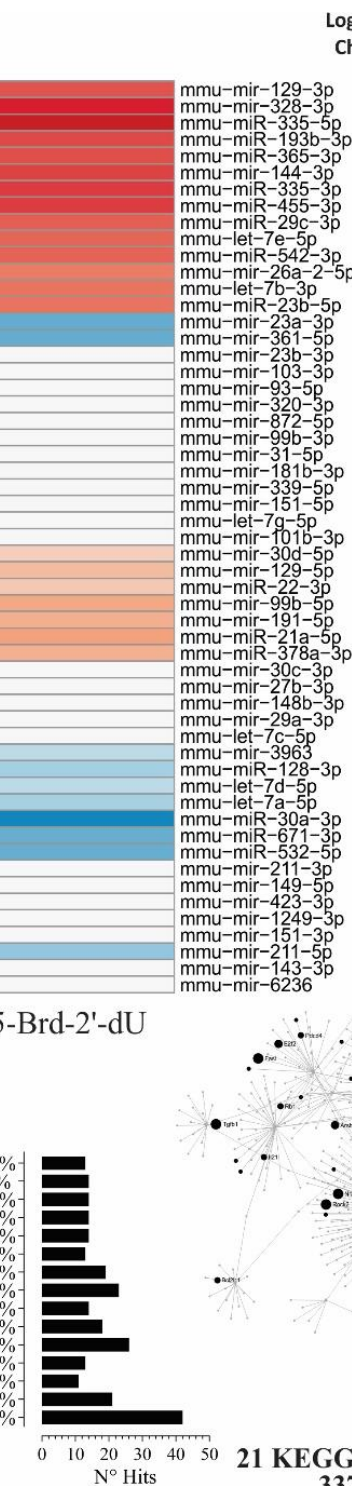

$\log _{2}$ Fold

Change

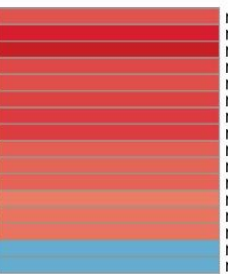

5

2.5

0

$-2.5$

$-5$

$$
\text { Sig }
$$

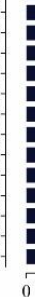

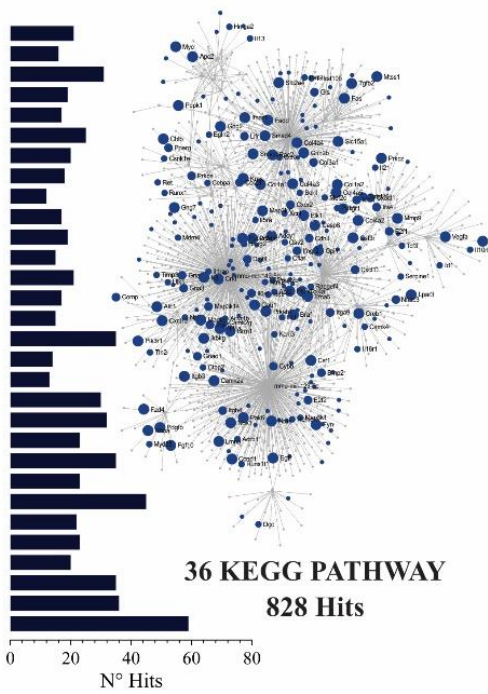

(c)

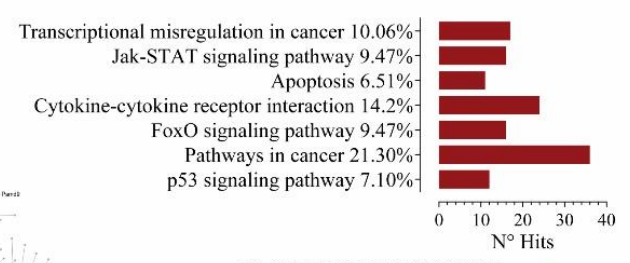

11 KEGG PATHWAY

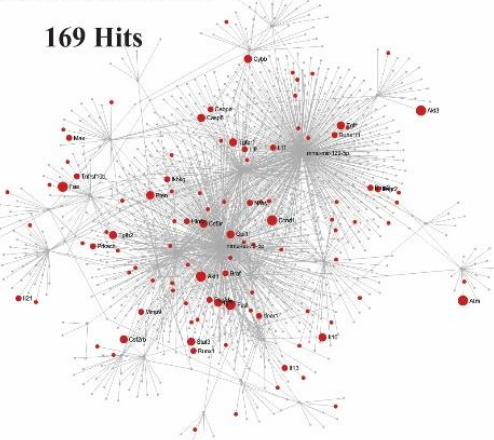

Figure 3. B16F1 cells induced to differential pigmentation and decreased proliferation, show changes in miRNA expression and, together with their molecular targets, make up potential gene interaction networks. (a) A heat map with the relative expression levels of 55 differentially expressed miRNAs, obtained by Small RNA-seq from B16F1 cells exposed to $5 \mathrm{mM}$ L-Tyr or $2.5 \mu \mathrm{g} . \mathrm{mL}^{-1}$ 5-Brd-2'-dU concerning non-exposed B16F1 control cells; red, expression up, blue, expression down, and white indicator of no variation. Differential expression by using the DESeq2 program. (b-d) Analysis of functional enrichment by KEGG signaling pathways of the potential interactions between differentially expressed miRNAs and their molecular targets in a network model, for exposure of melanoma cells to L-Tyr (b), 5-Brd-2'-dU (c), and 5-Brd-2'-dU with relative to L-Tyr $(\mathbf{d})$. The related KEGG signaling pathways were considered statistically significant for a $p$-value $<0.05$ after applying a hypergeometric test. 


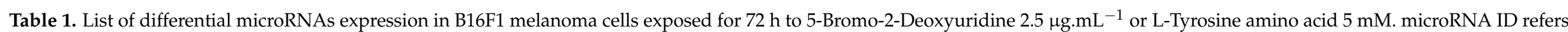

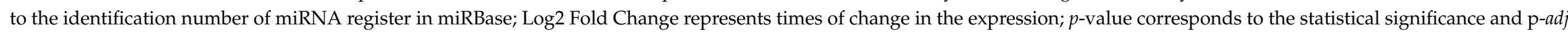
significance by multiple tests correction; baseMean means the average counts.

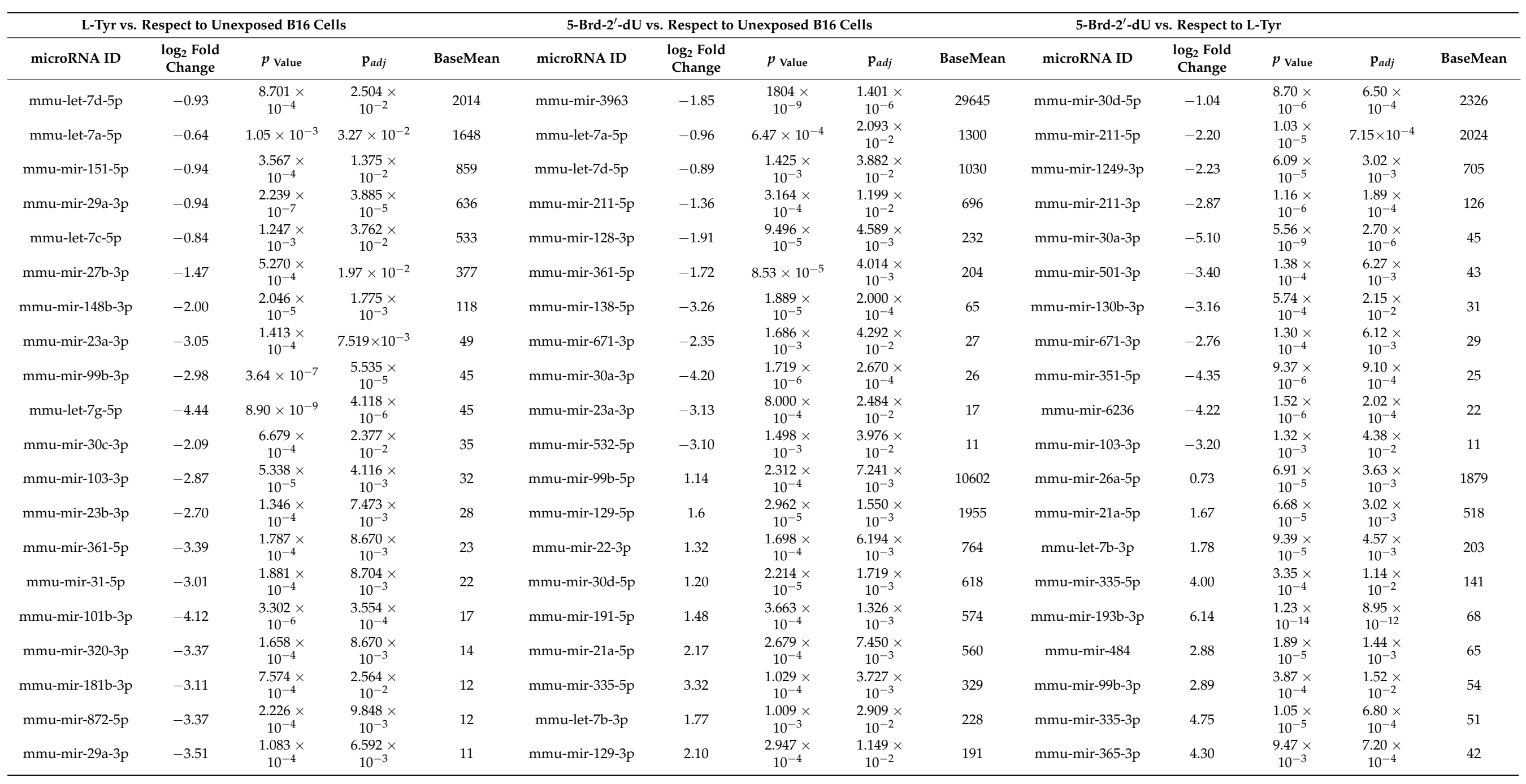


Table 1. Cont.

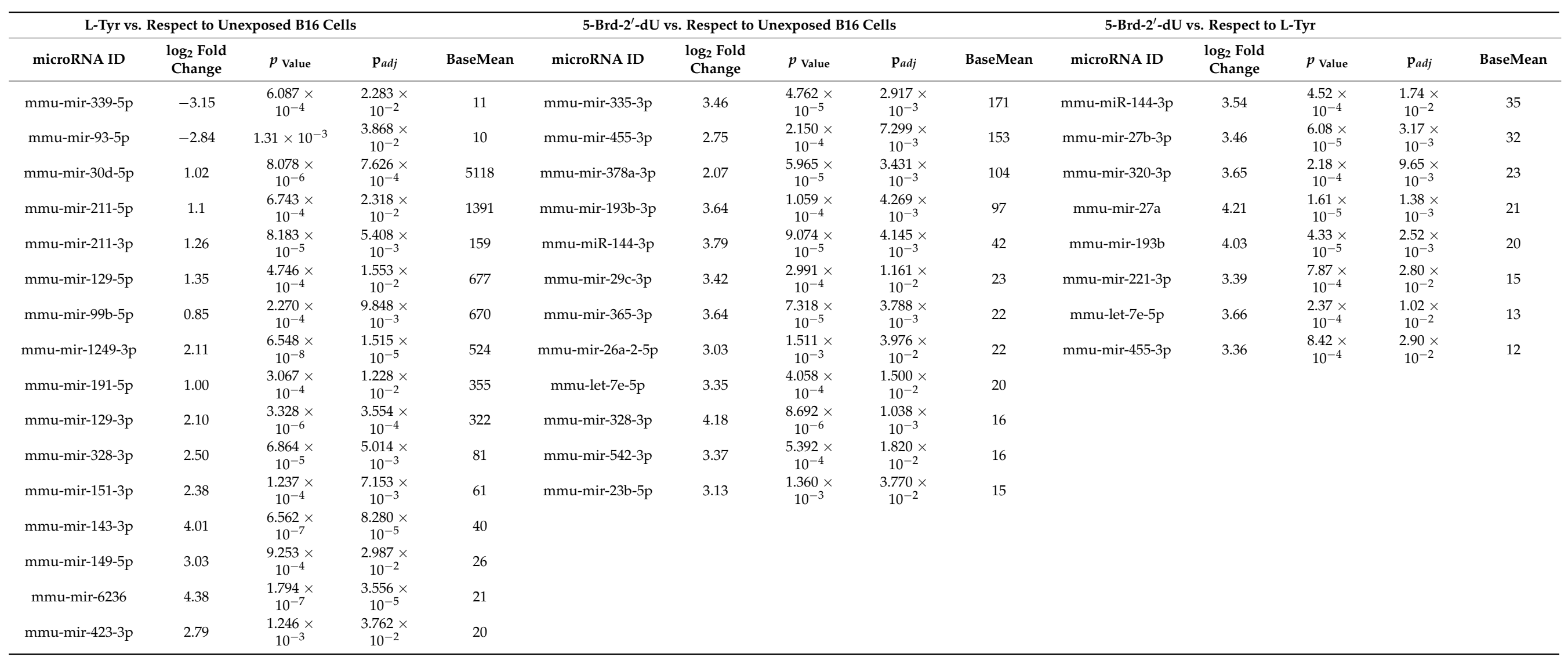


Similarities and differences in the expression of the miRNAs obtained in cells exposed to L-Tyr or 5-Brd-2'-dU concerning the control were shown with heat maps. We exclusively included the list of differentially expressed miRNAs (Figure 3a; Figure S2g,h). As shown in Figure $3 a$ the patterns obtained were common in overexpression for miR-30d-5p, miR-129$5 p$, miR-99b-5p, and miR-191-5p and of under-expression for members of the let-7 family (a-5p, d-5p), and the miRNAs, miR-23a-3p and miR-361-5p. The miR-211-5p was the only miRNA that presented overexpression in cells exposed to L-Tyr and under-expression with $5-\mathrm{Brd}-2^{\prime}-\mathrm{dU}$. However, the comparison of miRNAs differentially expressed in cells exposed to 5-Brd-2'-dU concerning L-Tyr yielded another set of miRNAs with orders in differential expression not visualized under the previous comparison exposure model the control (Table 1 and Figure S2f,i). Since this case's expression level was not the same, the exposure to L-Tyr or 5-Brd-2'-dU may generate changes in some miRNAs' expression in a differential way. (Figure S2i). Overall, the miRNAs' expression revealed a different expression profile in B16 cells in response to exposure to L-Tyr or 5-Brd-2'-dU. This profile was related to the observed differential pigmentation, proliferation, and senescence changes induced in this cellular model.

\subsection{Confirmation of miRNAs Differential Expression by RT-qPCR Stem-Loop and Prediction of miRNA Targets Associated with Induced Phenotypes}

We confirmed in terms relative differential expressions (rER) the expression of 7 miRNAs reported in Table 1 (211-5p, 30d-5p, 148b-3p, 129-5p, 27b-3p, 470-3p and 470-5p) by RT-qPCR stem-loop (Figure 4$)(n=3)$. miR-211-5p, increased $2.5 \mathrm{X}$ by exposure to L-Tyr and a decreased $2 X$, for 5-Brd-2'-dU (Figure 4a; Table 1). On the other hand, the overexpression of miR-30d-5p, increased by $5.4 \mathrm{X}$ and $8 \mathrm{X}$ (Figure 4c; Table 1) and of miR-129-5p, increased by $4.5 \mathrm{X}$ and $1.4 \mathrm{X}$ (Figure $4 \mathrm{c}$; Table 1 ) for exposure to L-Tyr and 5-Brd-2'-dU, respectively (Figure 4c; Table 1). RT-qPCR found miR-27b-3p, miR-148b-3p, a differentially expressed with values that did not agree in trend to those reported in Table 1 in DESEq2. Compared to the reduction registered by small RNAseq due to exposure to L-Tyr (miR-27b-3p 1.5 X and miR-148b-3p 2.0 X), by qPCR, both miRNAs increased their expression concerning the control (3.1 $\mathrm{X}$ and $4.5 \mathrm{X})$ respectively (Figure $4 \mathrm{c}$; Table 1). For exposure to $5-\mathrm{Brd}-2^{\prime}-\mathrm{dU}$, we found an increase ( $3.3 \mathrm{X}$ and $\left.3.55 \mathrm{X}\right)$ in expression by qPCR.

miRNAs showed common and coordinated expression patterns in this differential pigmentation and reduced proliferation induced in melanoma B16F1 cells. We identified potential targets of miRNAs by prediction with TargetScanMouse (Figure $4 \mathrm{a}-\mathrm{c}$ ). Some genes participated in controlling the cell cycle and senescence (i.e., Ccnd1, Cdk2, Cdk4, and p21/Cdkn1a, Rb1, E2F2, Atm, Foxm1, and E2F3). Other targets (i.e., Mitf, Tyr, Tyrp1, or $D c t$ ) were involved in melanin synthesis. miRNAs presented changes in their expression and targeted genes associated with controlling the cell cycle and senescence as expected (Figure 4a, Table 1).

\subsection{Regulatory Networks and Co-Expression Networks (RC-miR)}

The miRNAs are associated with melanoma's cellular processes independently; however, we intend to relate the effect they would have together and their potential molecular targets on the phenotype induced by L-Tyr y 5-Brd-2'-dU. We constructed possible gene interaction networks using the miRNet web application with the differentially expressed miRNAs, their putative genes, and functional enrichment analysis by KEGG signaling pathways (Figure 3b-d, Tables S1-S3 Functional Enrichment using KEGG).

In cells exposed to L-Tyr, enrichment revealed a total of 269 KEGG pathways, 2641 hits, and 1458 nodes; of which, 36 routes with 828 hits passed the hypergeometric test (Figure 3b). In cells exposed to 5-Brd-2'-dU, 256 KEGG pathways, 1560 hits, and 962 nodes; 11 routes and 169 hits with statistical significance (Figure 3c). Of these pathways, the regulation of proliferation, apoptosis, differentiation, survival, and pathways associated with cellular metabolism related to the phenotype induced by exposure to L-Tyr; while the p53, FoxO, apoptosis, Jak-STAT, and altered transcriptional regulation in cancer pathways related to the phenotype caused by exposure to 5-Brd-2'-dU. 


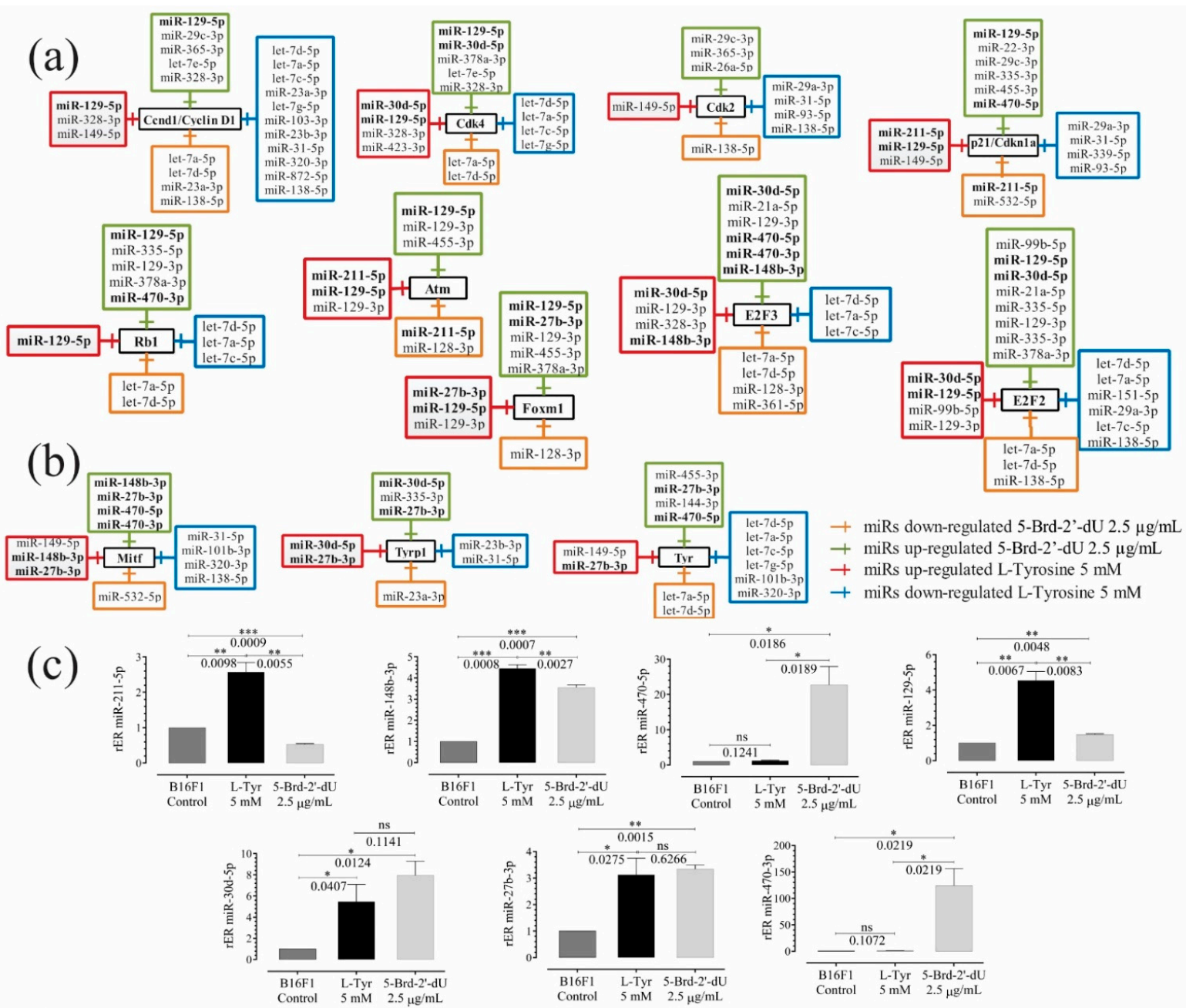

(d)

Down

$\mathrm{Up}$

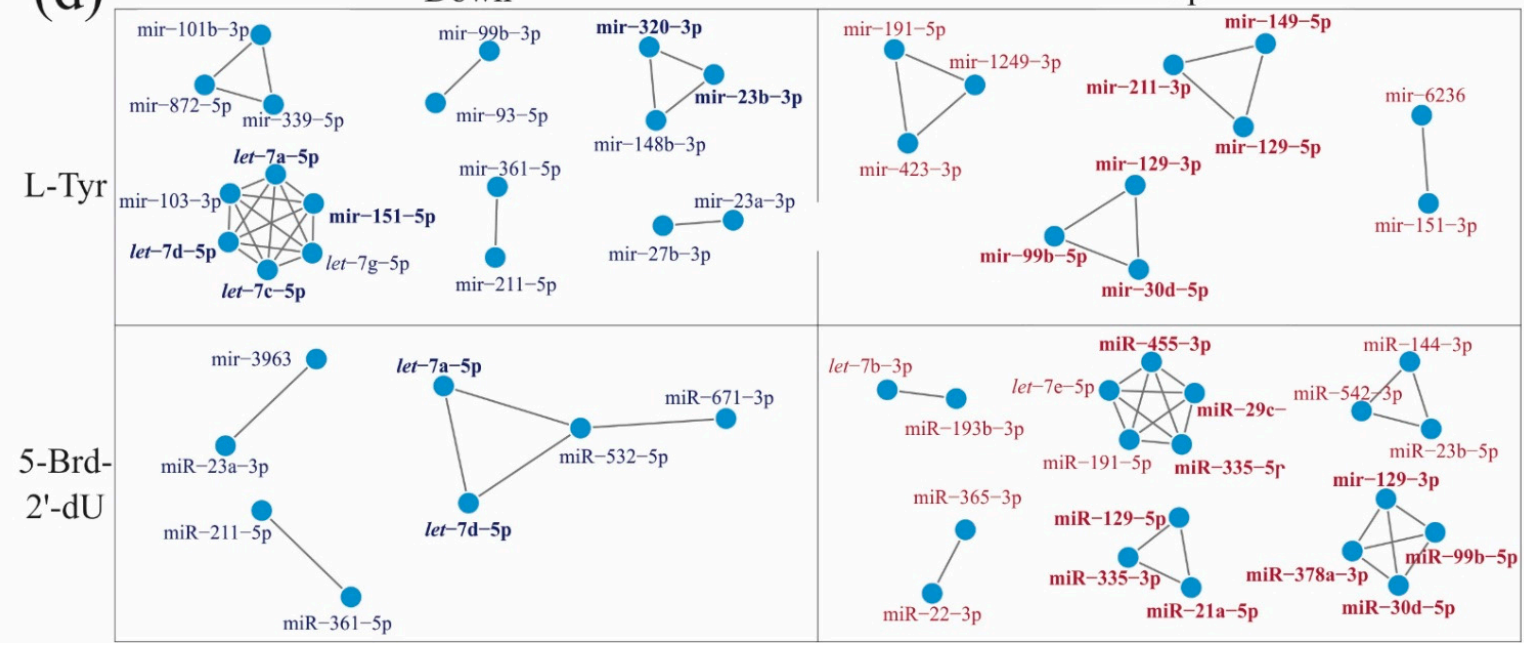

Figure 4. Sets of miRNAs show coordinated expression patterns in the differential pigmentation model and reduced proliferation induced in melanoma B16F1 cells. Sets of over-and under-expressed miRNAs and their potential candidate genes associated with cell cycle and senescence control (a) and melanogenesis (b) using the TargetScanMouse tool version 7.1. (c) Relative expression radius (rER) of miRNAs by RT-qPCR stem-loop for miRNAs 211-5p, 148b-3p, 470-5p, 129-5p, 27b-3p, 470-3p and 30d-5p $(n=3)$. (d) Co-expression networks from normalized Small RNA-Seq count of under-expressed miRNAs of B16F1 cells exposed to L-Tyr or 5-Brd-2'-dU. The level of significance $\left(^{*}\right)$ using two-tailed multiple $t$-tests. The differences were considered statistically significant for a $p$-value $<0.05$, ns: not significant. Significant $\left({ }^{*}\right)$ with $p<0.05$, very significant $\left({ }^{* *}\right)$ with $p<0.01$, highly significant $\left({ }^{* * *}\right)$ with $p<0.001$. 
We reviewed the gene regulation network constructed for the miRNAs differentially expressed in cells exposed to 5-Brd-2'-dU concerning L-Tyr. The network contained a total of 255 KEGG routes, 1671 hits, and 903 nodes; of which, 21 routes with 337 hits passed the hypergeometric test (Figure 3d). In this case, we observed other pathways involved, such as cell cycle, Wnt, and ubiquitin-mediated proteolysis. The data reported so far show the existence of a specific miRNA expression profile for each induced phenotype. This profile, seen from a network gene regulation model, would be associated with controlling different cellular programs through their target genes.

We used mutual information to measure similarity and co-expression networks (RCmiR) based on adjacency matrices for the differentially expressed miRNAs. As can be seen in Figure $4 d$, in cells exposed to 5-Brd-2'-dU, 9 clusters of miRNAs were identified, two of them over-expressed (miR-129-3p, miR-99b-5p, miR-378-3p, and miR-30d-5p) and (miR-129-5p, miR-21a-5p, and miR-335-3p), which according to TargetScan would have as a common target the factor E2F2; the cluster miR-455-3p, miR-29c-3p and miR-335-5p on $p 21$ and the cluster miR-29c-3p and let-7e-5p on Ccnd1 (Figure 4a). While for under-expressed miRNAs, we found the cluster let-7a-5p and let-7b-5p that would have as a putative target Tyr, Ccnd1, Cdk4, E2F2, E2F3, and Rb1.

In cells exposed to L-Tyr, 10 sets were found, of which, it was coincident with 5-Brd$2^{\prime}-\mathrm{dU}$, finding over-expressed miR-129-3p, miR-99b-5p, and miR-30d-5p and miR-211-3p, miR-149-5p and miR-129-5p clusters as a possible target of $p 21$. We found two clusters of potential regulators for Ccnd1: one with over-expressed miRNAs (miR-149-5p and miR-129-5p) and one under-expressed (miR-320-3p and miR-23b-3p), which could imply a coordinated regulation by expression to the high and low of the whole set of miRNAs. Regarding sets of under-expressed miRNAs, we found a cluster with the let-7 family (a, c, d) and the miR-151-5p, whose potential target was E2F2.

\subsection{Analysis of Differential Expression $m R N A$ s and Protein Level}

The mRNA expression levels of the selected genes were quantified by RT-qPCR, which we reported as the relative of differential expression (rER) concerning the housekeeping gene GAPDH and B16F1 cells. Western blot and immunofluorescence determined the expression and location of the corresponding protein. We evaluated some mRNAs involved in the cell cycle and senescence: Cyclin D1 (Ccdn1) expression, cyclin-dependent kinases Cdk4 and Cdk2, and the cyclin-dependent kinase inhibitor p21 (Figure 5). We evaluated the genes Tyr, Tyrp1, and Dct associated with melanogenesis and the master regulator of cell differentiation Mitf (Figure 6) for pigmentation phenotype. The relative expression (rER) of Ccnd1 decreased for L-Tyr by $0.47 \pm 0.16$ (2.5 X). Exposure to 5-Brd-2'-dU induced a decrease of $1.6 \times(0.6 \pm 0.06)$ (Figure $5 a)$.

The Cdk4 mRNA showed a decrease concerning the control cells only for L-Tyr with rER of $0.79 \pm 0.1(1.25 \mathrm{X}$ ) (Figure $5 \mathrm{~d}$ ). As is known, the sustained activation of the binding of the CCDN1 protein to the CDK4 protein kinase allows the early transition from G1 to $\mathrm{S}$ in the cell cycle, increasing the phosphorylation of the $\mathrm{Rb}$ retinoblastoma protein and releasing the E2F family of transcriptional regulators [38,39]. In both cases, the decrease in Ccnd1 was consistent with the increase in the number of cells arrested in G0/G1 observed in cells exposed to 5-Brd-2'-dU (Figure 1e). Although in Cdk4 it only presented a statistically significant reduction for exposure to L-Tyr, in both cases, the decrease in these mRNAs coincides with the increase in miR-129-5p and 30d-5p (Figure $4 \mathrm{~d}$ ), which as a predictor have $C d n 1$ and $C d k 4$ as molecular targets (Figure $4 \mathrm{a}$ ).

We observed a reduction in the Cdk2 in cells exposed to 5-Brd-2'-dU (0.36 \pm 0.09$)(2.7 \mathrm{X})$ and non-significant variation at the mRNA level (1.09 \pm 0.09$)$ (Figure 5g); however, at the protein level, we found changes for cells exposed to L-Tyr (Figure 5h,i). A set of miRNAs with regulatory potential for each type of treatment from the coincidences reported for $C c d n 1$ and $C d k 4$, except for miR-149-5p. 
(a)

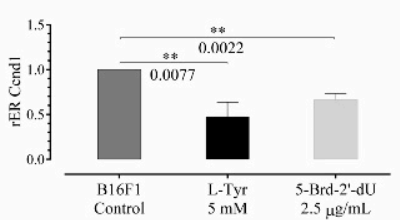

(b)
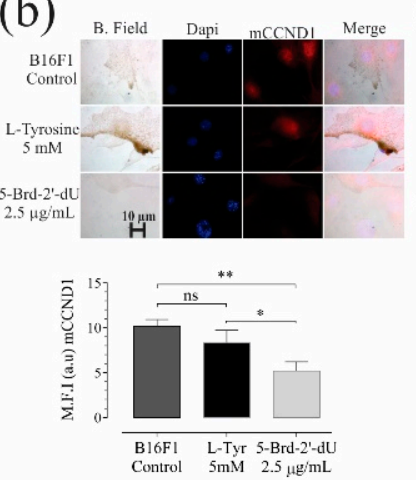

(c)

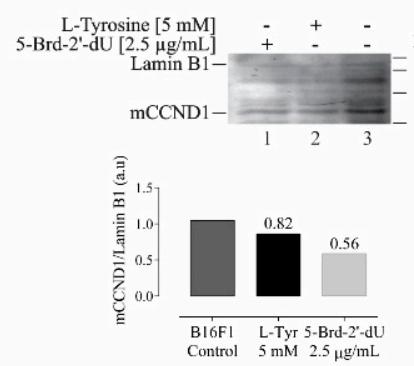

(d)

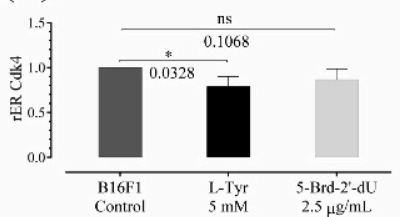

(e)

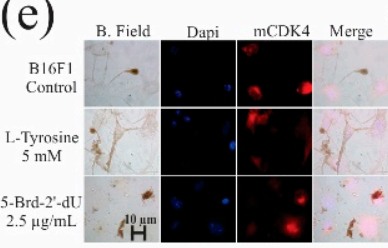

(h)

(g)

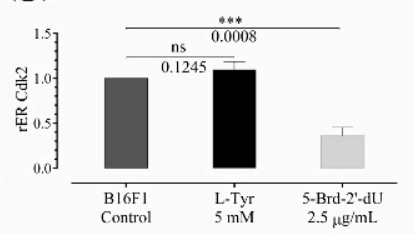

(i)

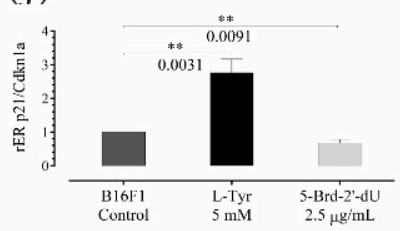

(k)

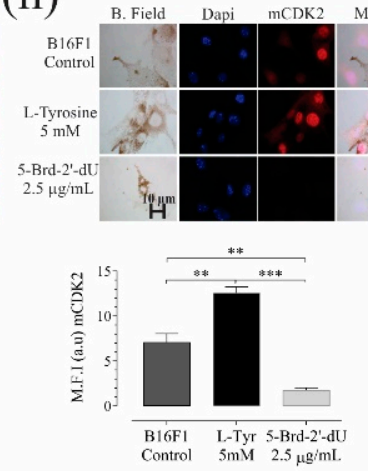

(i)

(f)
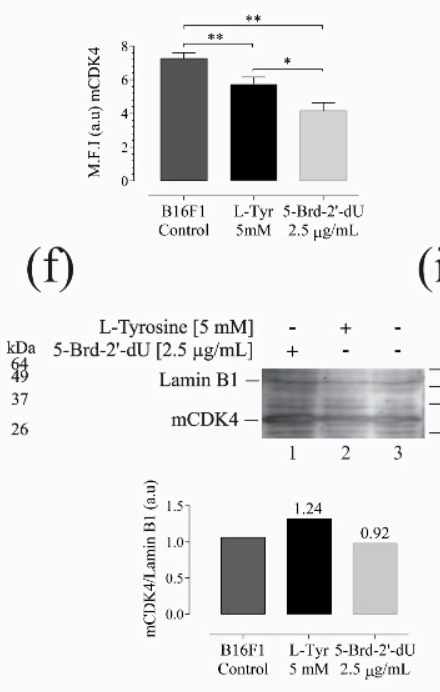

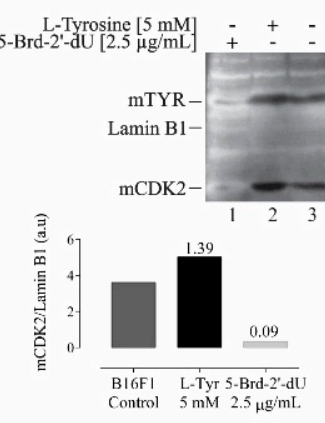

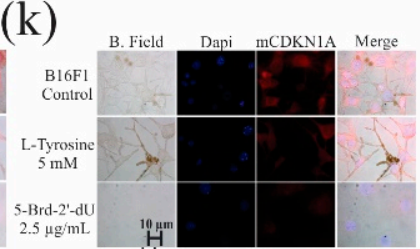

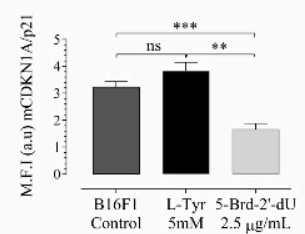

(1)

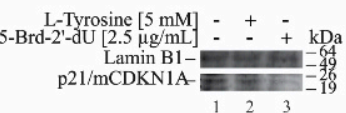

(m)

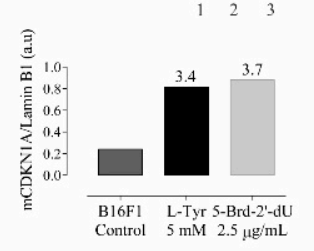

5-Brd-2'-dU $[2.5 \mu \mathrm{g} / \mathrm{mL}]$ $\mathrm{p} 21 / \mathrm{mCDKN} 1 \mathrm{~A}$

Figure 5. Variations in the expression of genes and their protein products, associated with controlling the cell cycle and senescence in B16F1 cells, induced differential pigmentation and decreased proliferation. Relative expression radius (rER) by RT-qPCR, $(n=4)$, representative photographs of the location and distribution by immunofluorescence (red) in nuclear counterstain with DAPI (blue), quantification of expression by mean fluorescence intensity (MFI), and western blot for CCnd1 $(\mathbf{a}-\mathbf{c}), \operatorname{Cdk} 4(\mathbf{d}-\mathbf{f}), \operatorname{Cdk} 2(\mathbf{g}-\mathbf{i})$ and p21 $(\mathbf{j}-\mathbf{m})$. The level of significance $\left.{ }^{*}\right)$ using two-tailed multiple $t$-tests. The differences were considered statistically significant for a $p$-value $<0.05$, ns: not significant. Significant $\left(^{*}\right)$ with $p<0.05$, very significant $\left.{ }^{* *}\right)$ with $p<0.01$, highly significant $\left.{ }^{* * *}\right)$ with $p<0.001$.

We founded the decrease in proliferation induced by L-Tyr and 5-Brd-2'-dU correlated with an increase in $p 21$ (rER $2.7 \pm 0.4)(2.7 \mathrm{X}$ ) for cells exposed to L-Tyr and an rER of $0.67 \pm 0.1(1.5 \mathrm{X})$ in cells exposed to 5-Brd-2'-dU (Figure 5j). This increase in $p 21$ would explain, at least in part, the decrease in the $\mathrm{S}$ phase for cells exposed to L-Tyr and CdK2 reduction with the arrest in G2/M (Figure 1e). The p21 expression increased after 7 days, maintaining the exposure (Figure $5 \mathrm{~m}$ ). In this case, the early regulation of the cell cycle by sets of miRNAs presents differential expression. They regulate other targets, such as p27 (increased in western for exposure to 5-Brd-2'-dU, data not shown).

Further, the exposure of B16F1 cells to 5-Brd-2'-dU generated a $4 \mathrm{X}$ decrease in the mRNA of all proteins related to melanogenesis, with rER values of $0.24 \pm 0.069$ for Mitf, $0.29 \pm 0.03$ for Tyr, $0.29 \pm 0.03$ for Tyrp 1, and in the case of Dct, $0.27 \pm 0.05$ (Figure 6a,, $\mathrm{j}$, respectively); additionally, this reduction related to the protein products obtained in each case (Figure $6 \mathrm{~b}, \mathrm{c}, \mathrm{e}, \mathrm{f}, \mathrm{h}-\mathrm{k}$ ). These results coincide with the drastic reduction in melanin observed in cells exposed to 5-Brd-2'-dU (Figure 1f) $[14,26,35]$. We did not find significant variations in the expression of Mitf mRNA $(1.12 \pm 0.4)$ (Figure 6a) and Tyrp1 $(0.85 \pm 0.09)$ (Figure 6g), but a significant increase for Tyr $(1.5 \pm 0.3)$ (Figure 6d), and Dct $(1.12 \pm 0.07)$ (Figure 6g). 
(a)

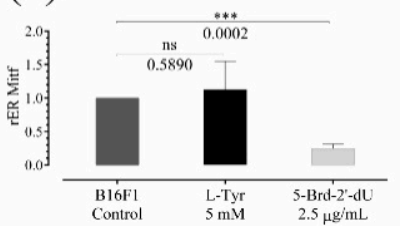

(b)

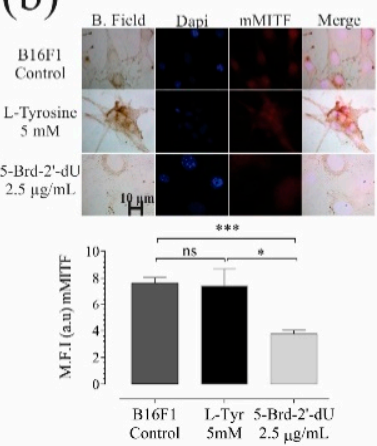

(c)
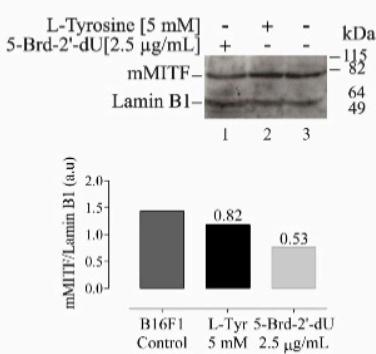

(d)

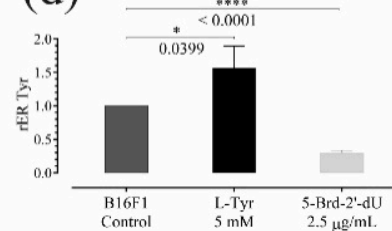

(e)

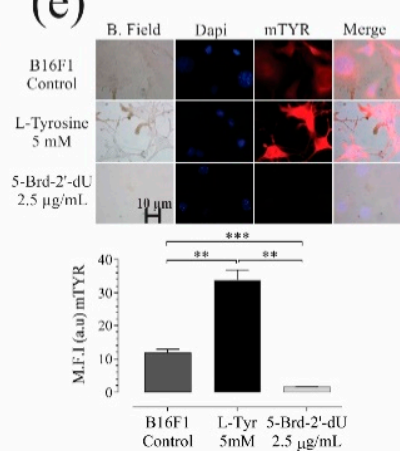

(f)

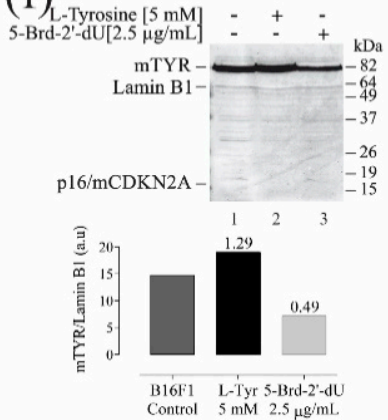

(g)

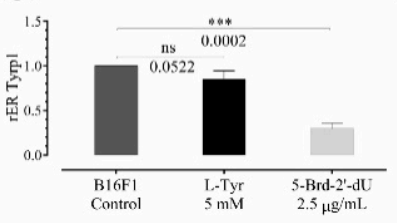

(h)

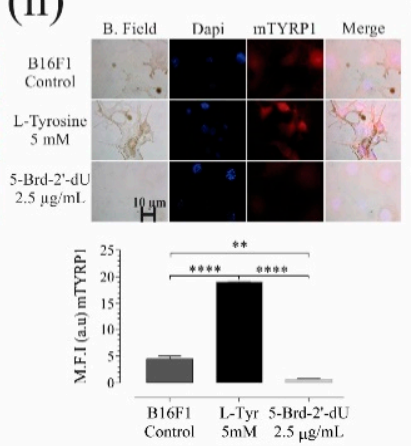

(i)

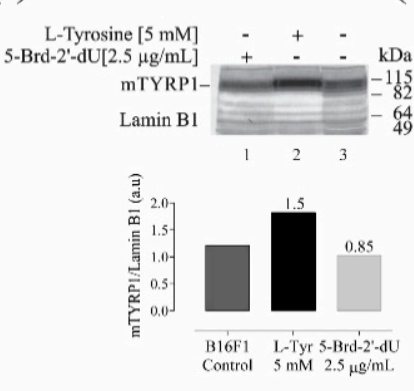

(j)

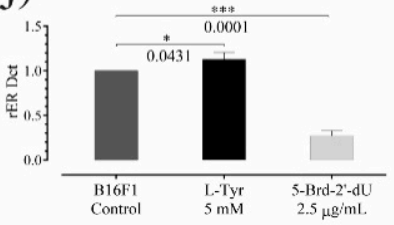

(k)

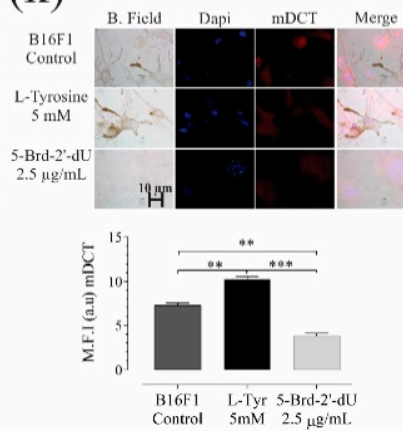

(1)

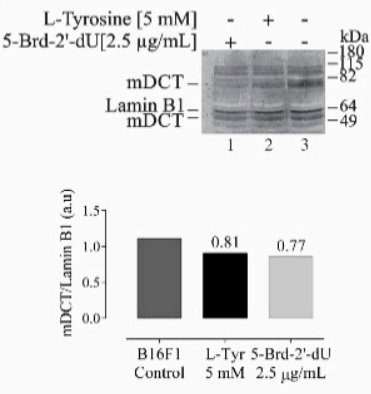

Figure 6. Variations in the expression of genes and their protein products are associated with melanogenesis in B16F1 cells induced at differential pigmentation and a decrease in proliferation. Relative expression radius (rER) by RT-qPCR, $n=4$, representative photographs of the location and distribution by immunofluorescence (red) in nuclear counterstain with DAPI (blue), quantification of expression by mean fluorescence intensity (MFI), and western blot for the master regulator of melanocyte cell differentiation-MITF $(\mathbf{a}-\mathbf{c})$, and the enzymes Tyr $(\mathbf{d}-\mathbf{f}), \operatorname{Trp} 1(\mathbf{g}-\mathbf{i})$, and Dct $(\mathbf{j}-\mathbf{l})$. The level of significance $\left({ }^{*}\right)$ using two-tailed multiple $t$-tests. The differences were considered statistically significant for a $p$-value $<0.05$, ns: not significant. Significant $\left(^{*}\right)$ with $p<0.05$, very significant $\left({ }^{* *}\right)$ with $p<0.01$, highly significant $\left({ }^{* *}\right)$ with $p<0.001$ and very highly significant $\left.{ }^{* * * *}\right)$ with $p<0.0001$.

\section{Discussion}

The number of reports related to changes in miRNAs' expression and their targets in melanoma samples under different tumor progression stages is growing; however, their role in growth suppression models and whether these miRNAs change reciprocally with the phenotype are little known. We present the first report about changes in miRNAs' expression profile in mouse B16 melanoma cells under growth suppression and differential pigmentation induced by exposure to the amino acid L-Tyrosine or the thymidine analog 5-Bromo-2'-deoxyuridine. We propose some network models of co-expression of microRNAs that present potential common targets associated with cell cycle control, senescence, proliferation, and melanogenesis in the mouse melanoma B16-F1 cells.

Exposure for $72 \mathrm{~h}$ to L-Tyr and 5-Brd-2'-dU generates a statistically significant decrease in the number of B16F1 cells (79\% and 64\%, respectively (Figure 1b and Figure S1c)), results that agree with previous reports on B16 cells and other models of melanoma, such as embryonic retinal pigment cells and IIB-MEL-J [15,19-22,40]. To discriminate the loss of cells by death and cell cycle arrest, we quantified the number of cells in supernatants by I.P. 
incorporation, and we calculated the population doubling times (Figure 1d; Figure S1b,c). The increase from $19.6 \pm 3.94 \mathrm{~h}$ to $48.67 \pm 6.25 \mathrm{~h}$ and $27.03 \pm 3.0 \mathrm{~h}$ induced by 72 -h exposure to L-Tyr and 5-Brd-2'-dU, respectively, indicates that reduction of the number of cells would be mainly a consequence of variations in the cell cycle control. Cell cycle analysis (Figure 1e), indicating a transition of the G0/G1 phase (from $50 \pm 3.0 \%$ to $66.6 \pm 2.8 \%$ ) and G2/M (from $15.7 \pm 1.6 \%$ to $2.4 \pm 1.2 \%$ ) for 5 -Brd-2'-dU and in the S phase for L-Tyr (from $24.4 \pm 0.7 \%$ to $15.8 \pm 3.6 \%$ ). The cells exposed to L-Tyr significantly increase the G0/G1 phase $(55.5 \pm 3.8 \% n=3)$.

p16 is mutated in B16 cells [41] (not shown data); therefore, we decided to evaluate the expression of $p 21$ to understand the decrease in proliferation induced by L-Tyr and 5-Brd-2'-dU. Cells exposed to L-Tyr increase the $p 21$ expression with an rER $2.7 \pm 0.4$ (2.7 X), and cells exposed to 5-Brd-2'-dU decrease $p 21$ with an rER of $0.67 \pm 0.1(1.5 \mathrm{X})$ (Figure 5j). This increase in $p 21$ would explain, at least in part, the decrease in the $S$ phase for cells exposed to L-Tyr (Figure 1e), while the reduction of p21 is related to the arrest in G2/M in CdK2 in 5-Brd-2'-dU (Figure 1e) [42-45]. CDK2 is a cyclin-dependent kinase that participates in the late transition of G1/S by binding to cyclin E [46] and in the passage of G2/M by binding to cyclin A [47]. The late participation of p21 in regulating the cell cycle under exposure to 5-Brd-2'-dU [27] agrees with its high expression after seven days of maintaining the treatment (Figure $5 \mathrm{~m}$ ).

B16F1 melanoma cells under standardized cell culture conditions [15,25] and 5-Brd$2^{\prime}$-dU $[14,21,26,35]$ presented changes in melanin concentrations (Figure 1b) (Pearson's correlation coefficient 0.999 ). Fluorometry and colorimetry allowed the detection of increase $(9 \mathrm{X})$ and decrease $(5 \mathrm{X})$ in melanin concentration in B16 cells exposed to L-Tyr and 5-Brd-2'-dU, respectively (Figure 1f). However, fluorometry was more sensitive (detection limit $0.098 \mu \mathrm{g} . \mathrm{mL}^{-1}$ and $\mathrm{CV}$ of $9.85 \%$ ); this hyperpigmentation has also been described in primary culture melanocytes exposed to high concentrations of the amino acid L-tyrosine $[48,49]$.

We confirm that exposure to L-Tyr and 5-Brd-2'-dU induces an arrest at different points in the cell cycle control for B16F1 cells and differential pigmentation phenotype associated with changes in the expression of genes involved in melanin synthesis $[17,31,50]$. L-Tyrosine and the thymidine analog, 5-Bromo- $2^{\prime}$-deoxyuridine induced a decrease in proliferation and pigmentation changes in melanoma B16F1 cells. These phenotypic changes remember terminal differentiation and replicative senescence induced by L-Tyr and 5-Brd-2'-dU, respectively.

5-Brd-2'-dU's replicative senescence generates a phenotype associated with induced senescence in different cell models [27-29], including B16 cells [30,31,51]. Senescenceassociated beta-galactosidase (S.A. $\beta$-Gal) assay (Figure $2 b$ ) and positivity for the histone $\mathrm{H} 3 \mathrm{~K} 9 \mathrm{me} 3$ involved in heterochromatin remodeling confirm the senescence phenotype $[52,53]$. Cells exposed to 5-Brd-2'-dU show many concentrated foci, which are associated with heterochromatin (SAHF). Some of these SAHF coincide with a greater density obtained by DAPI labeling (Figure 2c) [32]. Overall, the results of exposure to 5Brd- $2^{\prime}$-dU suggest a phenotype associated with senescence and agree with that previously reported in 5-Brd-2'-dU-induced senescence models [33,34]. Exposure to L-Tyr induces complexity (SSC) and increases cell size (Figure 2d), perhaps due to the increased number of melanosomes required to synthesize and store the melanin produced $[20,54,55]$.

A global change in miRNA expression profiles by exposure to L-Tyrosine generated $61 \%$ of under-expressed miRNAs and 39\% over-expressed, compared to $34 \%$ and $65 \%$ $5-\mathrm{Brd}-2^{\prime}-\mathrm{dU}$. These results suggest that 5-Brd-2'-dU's melanoma cells exposed to genotoxic or metabolic stress by L-Tyr generate two expression profiles for the same genetic background, explaining the reduction in growth and changes in the pigmentation described here, depending on the potential regulation on its molecular targets.

As expected, the results presented here contrast with previous reports of miRNA expression profiles already obtained under discrete stages of melanoma progression. For example, miR-211-5p in this experimental model is over-expressed by the exposure to L-Tyr; 
in contrast, during tumor progression, miR-211-5p tends to decrease [56-58]. For the let-7a family members, under-expressed in both L-Tyr and 5-Brd-2'-dU or let-7b overexpressed in 5 -Brd-2'-dU and reported as a cell cycle regulator in melanoma, possibly through cyclins D1 and $D 3$ and $C d k 4$ and associated with interference with anchorage-independent growth [59]. miR-455, high in B16 cells exposed to 5-Brd-2'-dU and low in tumor progression $[58,60]$. These findings agree with the notion that some miRNAs are known to participate in tumor progression as a tumor suppressor, oncomiRs, or miRs and may involve a possible reversible tumor reprogramming mechanism through their targets, in processes that include cell proliferation, senescence, and melanogenesis.

5-Brd-2'-dU is a potent tumor cell radiosensitizer [61]. Its incorporation into DNA generates lesions that include mutations, fragile sites, chromatid-cracking and exchange, micronuclei, and hypermethylation [27]. DNA damage produces disruptive effects in the patterns of DNA transcription, increase the affinity of nuclear factors, altering the binding of regulatory proteins to the DNA, which may result in changes in cell differentiation, suppressing cell proliferation, and even causing alterations in the plasma membrane cells $[21,22,27,33,34,61-64]$.

The results presented herein B16 cells on microRNA expression changes extend our knowledge on other molecular effects generated by 5-Brd-2'-dU exposure in terms of a possible regulation of these processes mediated in a post-transcriptional manner. In B16F1 melanoma cells, 5-Brd-2'-dU causes an absence of melanosomes, an interruption of the lamellar matrix of the endoplasmic reticulum, and an irregular perinuclear microfilament arrangement [18].

We observed changes at the mRNA and protein levels for Tyr and Dct and protein for Tyrp1 without Mitf gene expression changes, suggesting that other regulatory mechanisms are related, i.e., regulation mediated by sets of miRNAs. Downregulation of tyrosinase gene expression by $5-\mathrm{Brd}-2^{\prime}-\mathrm{dU}$ is not due to incorporating this analog into upstream sequences of the tyrosinase gene. Therefore, the mechanism of pigment inhibition is not elucidated yet $[21,26,65]$. In contrast, in cells exposed to L-Tyr, the Mitf values did not present statistically significant changes concerning the control cells (Figure 6). As shown here, cells exposed to 5-Brd-2'-dU and a decrease in Mitf, the master regulator of melanogenesis, modulate Tyrosinase, Tyrp1, and Dct gene expression [20,55,66-69] and through the coordinated and simultaneous gene activity interference.

Pigmentation changes in this model are not mutually exclusive with the suppression of cell growth, which supports the idea of multiple signaling pathways and molecular networks operating differentially to generate a reduction in cell proliferation with differentially hyper or hypopigmentation phenotypes. Perhaps the latter, as a consequence of the phenotype associated with senescence due to $5-\mathrm{Brd}-2^{\prime}-\mathrm{dU}$ exposure, evidence widely reported in other models where 5-Brd-2'-dU generates hypopigmentation $[21,26,70]$.

The confirmation of differential expression of some miRNAs by RT-qPCR stem-loop and the prediction of miRNA targets associated with induced phenotypes reveals a different set of miRNAs per challenge 5-Brd-2'-dU and Tyr the differential pigmentation phenotype. However, we did not find miRNAs with differential expression by TargetScan that had Dct as a target and for miR-27b-3p, which has Mitf, Tyr, and Tyrp1 as a common target and miR-148b-3p, reported as a Mitf regulator [71], DESEq2 and RT-qPCR found nonconcordant values. In this regard, for exposure to L-Tyr, in PCR, both miRNAs increased their expression concerning the control, a situation also recorded for exposure to 5-Brd-2' $\mathrm{dU}$, a differential expression that was not obtained by sequencing (Figure 4c). This apparent miRNA antagonism is frequent when the differential expression analysis is assessed by different platforms, including microarrays, NGS, and RT-qPCR. It would possibly be associated with the technical effects of each methodology [72], for what was considered the analysis of expression by PCR as gold standard [73].

miR-470-5p targets Mitf that regulate Tyr enzyme, which is a target of miR-470-3p; had already been reported before by our laboratory [18]. Here we confirmed by RT-qPCR (Figure 4c), with an increase due to exposure to 5-Brd-2'-dU (22 X for miR-470-5p), but 
not for L-Tyr. These two miRNAs participate in the differentiation of mouse embryonic cells [74] and hepatocellular carcinoma [75]. Our results show that their potential role in the CCDN1/CDK4 complex as an essential oncogenic driver in various cancer types, including melanoma [76].

The let-7 family's downward expression agrees with the previous publications $[58,77,78]$ through binding to $\beta 3$ integrin [79] and the miR-125a-5p/Lin28B/let-7 regulatory circuit [80], metastasis [81], metabolism [82], and the control of the cell cycle by CDK4 and cyclins D1, D3, and A [59].

miR-129-5p has been reported in the increase in the size of A375 cells through binding to AEG1 [83]. In other types of cancer, this miR is related to cell cycle control, proliferation, migration, and invasion [84] in multiple myeloma, glioma cells [85,86], prostate cancer $[87,88]$, colorectal cancer [89], and breast cancer [90].

miR-30 family is related to the regulation of proliferation processes via Wnt/ $\beta$ catenin [91,92], cell cycle control [93], apoptosis [94,95] and senescence in various cell models $[96,97]$. In melanoma, it is related to increased cell invasion due to increased aberrant glycosylations associated with its molecular target GALNT7 [98].

Pigmented and unpigmented B16 melanoma cells present an expected decrease in cell proliferation. It is possible to suggest that miRNAs share, through their potential targets, a reciprocal and coordinated regulation on the cell cycle's control dependent on the expression level of the specific group of miRNAs, without ignoring the possible differential effect that the regulation of each of them would exert.

L-Tyr induces melanin production and increases the synthesis of proteins related to melanogenesis as previously reported [55,99], trends confirmed in B16F1 cells exposed to L-Tyr (Figure 1f). Mitf did not change in cells exposed to L-Tyr; therefore, the differences found at the mRNA and protein levels for TYRP1, as well as the increase in TYR and DCT suggested that, in melanogenesis, other types of post-transcriptional regulation would be involved, such as the differential expression of sets of miRNAs: miR-211-5p and miR-148b$3 p$, previously reported as regulators of the pigmentation. Different miRNAs regulated Mitf and, in turn, is a transcriptional regulator of $p 21, C d k 2$ [100-102] and miR-211-5p, the latter, which regulates pigmentation by targeting EDEM1, a TYR inhibitor. miR-211-5p increased to $2.5 \mathrm{X}$ by exposure to L-Tyr and decreased $2 \mathrm{X}$ by $5-\mathrm{Brd}-2^{\prime}-\mathrm{dU}$. We did not find a miR-211-5p direct specific gene target involved in the melanogenesis. However, this was the only miRNA that showed differences between the two phenotypes-pigmented and unpigmented melanoma cells. It is exciting that miR-211-5p has been proposed as an indirect regulator of pigmentation through binding to the TGF $\beta-2$ receptor, a factor responsible for the transcription of pigmentation-associated genes Dct, TYRP1, TYR, and PMEL17 [103] and binding to the TYR inhibitor EDEM1 mRNA [104]; additionally, MITF may regulate the expression of miR-211-5p [103]. Together, these results suggest a possible pigmentation regulatory circuit in which genes regulated by miR-211 and the MITF factor would be participating, including the coordinated expression of sets of miRNAs.

The analysis of functional enrichment by KEGG pathways for the differentially expressed miRNAs shows diametrically compromised pathways for each phenotype that reinforce the hypothesis of miRNAs that operate in the regulation of signaling pathways under metabolic stress generated by exposure to L-Tyr (PI3K/Akt, MAPK, mTOR, among others) and miRNAs with potential participation in response pathways to genotoxic stress (p53, FoxO, Jak-STAT and transcriptional alteration in cancer).

Coordinated and reciprocal miRNA expression changes may explain changes in melanoma phenotypes induced by L-Tyr and 5-Brd-2'-dU. miR-211-5p is overexpressed in the hyperpigmented phenotype and downward in the hypopigmented phenotype, without ignoring other miRNAs' possible participation such as miR-470-5p miR-148-3p, miR-30d$5 \mathrm{p}$, and miR-27b-3p, which have Mitf, Tyr , and Tyrp1 as potential molecular targets. It was striking that exposure to L-Tyr did not affect the expression levels of the gene and protein of MITF, the master regulator of the expression of TYR, TYRP1, and DCT, but for the levels of Tyr mRNA, an increase with statistical significance. These results suggest an additional 
regulation to the transcription factor, possibly involving miR-211-5p, as has already been reported in other models [104].

Regarding the control of the cell cycle and senescence in B16F1 melanoma cells, where p16INK4a is truncated [41], suggests other pathways involved, such as p21, p53 pathway, cyclin D1, Cdk2, Cdk4, Rb, and transcription factors E2F [105-107].

This bioinformatics approach based on experimental data of differential expression of miRNAs could facilitate the establishment of new hypotheses associated with a differential expression profile, whose expression as a whole could be related to the synchronous regulation of gene expression in particular cellular programs. Recent evidence suggests a possible epigenetic reprogramming by transcriptional modification of miRNA expression profiles [108]. Based on the results in this experimental model of induced growth suppression and differential pigmentation, cells may reprogram a reversible phenotype through the coordinated and reciprocal regulation of their transcriptome. It is tempting to speculate a possible coordinated response under the stimulus of genotoxic or metabolic stress described above. This response involves the global reprogramming of patterns of miRNA expression and miRNAs relative antagonism.

A parallel reprogramming in mRNA expression may provide a partial explanation for the changes reported in cell cycle control, senescence, and melanogenesis; new studies are necessary to understand the molecular bases of miRNAs and epigenetic regulation. However, it is necessary to confirm the clusters generated here in the network models and establish the functional network associations between these microRNAs and their mRNAs target in cell cycle control and pigmentation.

The results apply only to the murine melanoma cell line B16 under specific experimental conditions of this study. They do not allow for any generalization and cannot extrapolate the results found in our work to another melanoma model given the high biological variability. In this regard, we compared the same population of the cell line under two different phenotypes to have the same genetic background to decrease biological variability. While a basis for comparison is still maintained, many differences between cell lines and primary cell cultures and the heterogeneity in melanoma from biopsies or surgical specimens may limit these findings' relevance to the miRNA expression. They may be different and questionable for the genetic variations. Therefore, it is necessary to confirm the findings in other melanoma cells, especially in primary human melanoma cultures.

\section{Materials and Methods}

\subsection{Cell Line Cultures}

The B16F1 tumor cell line: (ATCC ${ }^{\circledR}$ CRL-6322 ${ }^{\mathrm{TM}}$, Manassas, VA, USA), with epithelial morphology and adherent growth, from C57BL/6 J mouse skin, was cultivated at $37^{\circ} \mathrm{C}$ with 5\% $\mathrm{CO}_{2}$ and $98 \%$ humidity (Precision Scientific NAPCO 5410-120 Water Jacketed $\mathrm{CO}_{2}$ Incubator, Buffalo, NY, USA) in DMEM advance (Dulbecco's modification of Eagles medium) (Gibco, Thermo Fisher Scientific, Waltham, MA, USA) supplemented with $10 \%(v / v)$ fetal bovine serum (SFB) (Gibco), $\mathrm{pH} 7.2-7.4$ condition, penicillin $(100 \mathrm{U} / \mathrm{mL})$, and streptomycin $(100 \mu \mathrm{g} / \mathrm{mL})$. The cells, at $70 \%$ confluence, treated with trypsin-EDTA (Sigma-Aldrich, St. Louis, MO, USA) $0.25 \%(\mathrm{~m} / \mathrm{v})$, resuspended and counted in automatic Tali $^{\mathrm{TM}}$ Image-based Cytometer (Thermo Fisher Scientific) following the manufacturer's specifications and their viability evaluated in Newbauer's Chamber in dilution 1:1 with Trypan Blue (Sigma-Aldrich).

\subsection{Induction of the Phenotype of Decreased Proliferation and Changes in Pigmentation by Expo-Sure to L-Tyrosine (L-Tyr) or 5-Bromo-2'-Deoxyuridine (5-Brd-2'-dU)}

We seeded an average of $1.5 \times 10^{5} \mathrm{~B} 16 \mathrm{~F} 1$ cells in complete DMEM in a sterile Petri dish (Falcon 3003). Between 10 to $12 \mathrm{~h}$ after sowing, we changed by fresh medium supplemented with 5-Brd-2'-dU (Sigma-Aldrich) or L-Tyr (Biomedical Inc, Clinton Township, MI, USA) at a final concentration of $2.5 \mu \mathrm{g} / \mathrm{mL}$ and $5 \mathrm{mM}$, respectively, and incubate for $72 \mathrm{~h}$ without 
medium change. Furthermore, we followed every $48 \mathrm{~h}$ for cell monitoring assay until $240 \mathrm{~h}$, where $5.0 \times 10^{2}$ cells were seeded to determine population doubling times. The photomicrographs were captured under a 20x inverted light microscope (Nikon Eclipse Ti, Kobe, Japan) using the NIS-Elements-Nikon program. The cells treated with 5-Brd-2' $\mathrm{dU}$, protected from light, were resuspended in complete medium, and the exclusion of Trypan Blue assessed the viability. Additionally, the cells from the culture supernatants recovered by centrifugation, and their viability was determined using propidium iodide (I.P.) incorporation assay in Tali ${ }^{\mathrm{TM}}$ Image-based Cytometer following the manufacturer's specifications.

\subsection{MTT Assay}

B16F1 cells exposed or not to L-Tyr or 5-Brd-2'-dU were seeded in a sterile 96-well culture box (Corning, NY, USA); after 10-12 $\mathrm{h}$ of incubation, the medium was removed and incubated again for $1 \mathrm{~h}$ at $37^{\circ} \mathrm{C}$ with $0.83 \mathrm{mg} \cdot \mathrm{mL}^{-1}$ of MTT (3 (4.5 dimethylthiazol) 2.5 diphenyl tetrazolium bromide) (Sigma-Aldrich) dissolved in phosphate-buffered saline (PBS). We removed the MTT excess MTT, and dimethyl sulfoxide (DMSO) (Merck, Branchburg, NJ, USA) to help to dissolve the formazan crystals. The wells were read at $560 \mathrm{~nm}$ on a GloMax ${ }^{\circledR}$-Multi Detection System (Promega, Madison, WI, USA) following the manufacturer's specifications. To determine the diluted formazan crystals' proportionality with the number of viable cells, we constructed a calibration curve using six serials 1:2 dilutions from $8.0 * 10^{4}$ cells. Each well-read read under the same conditions. We assessed population doubling time following the reported protocol [109].

\subsection{Univariate Analysis of Cell Cycle by Incorporation of Propidium Iodide}

For the cell cycle analysis, we followed the previously reported protocol [110]. In brief, a total of $1.0 * 10^{6} \mathrm{~B} 16 \mathrm{~F} 1$ cells exposed or not to L-Tyr or 5-Brd-2'-dU were fixed in $75 \%(v / v)$ ethanol for $2 \mathrm{~h}$ at $4{ }^{\circ} \mathrm{C}$. Excess ethanol was removed and washed with PBS, and the cell pellet was resuspended in propidium iodide (P.I.) staining solution containing: $0.1 \%(v / v)$ Triton X-100 (Sigma-Aldrich); $10 \mu \mathrm{g} \cdot \mathrm{mL}^{-1}$ of propidium iodide (Sigma-Aldrich) and $100 \mu \mathrm{g} / \mathrm{mL}$ of DNase-free RNase A (Thermo Fisher Scientific) in PBS, protected from light for $30 \mathrm{~min}$ at $\mathrm{T}^{\circ}$ room. The cells were analyzed at a flow cytometer (BD FACSAria II TM, Franklin Lakes, NJ, USA). The fluorescence was measured at $536 \mathrm{~nm}$ and $617 \mathrm{~nm}$ for excitation and emission, respectively, a total of $1.0 \times 10^{4}$ events in three independent replicates. We estimated the relative number of cells using the FlowJo ${ }^{\mathrm{TM}}$ program that assumes Gaussian distributions of the $2 \mathrm{~N}$ and $4 \mathrm{~N}$ populations and using a subtractive function to establish the $S$ phase population. Additionally, the cytometer classified the cells according to their size (FSC-A) and its graininess or morphological complexity (SSC-A). Analysis of statistical significance for multiple comparisons without correction, with an alpha $=0.05$.

\subsection{Melanin Quantification}

Melanin was quantified by spectrophotometry and fluorometry following previously reported protocols $[23,24]$. In short, we dissolved synthetic melanin (Sigma-Aldrich) $100 \mu \mathrm{g} / \mathrm{mL}$ and melanin from B16F1 cells with $1 \mathrm{M} \mathrm{NaOH}$ (Merck) at $80^{\circ} \mathrm{C}$, the collected supernatants after centrifugation $\left(1 \mathrm{~min}\right.$ at $12,000 \times \mathrm{g}$ at $\left.4{ }^{\circ} \mathrm{C}\right)$, and we assess the optical density (O.D.) by spectrophotometry at $405 \mathrm{~nm}$. For fluorescence melanin quantification, after incubation with $15 \%(m / v)$ hydrogen peroxide $\left(\mathrm{H}_{2} \mathrm{O}_{2}\right)$ (Sigma-Aldrich), we read the supernatants on the Glomax equipment with a wavelength of $470 \mathrm{~nm}$ and $550 \mathrm{~nm}$ excitation and emission, respectively. We described the results according to the number of viable cells after determining cell number by MTT reductase assay. Data were expressed as the average of three independent trials \pm standard deviation and analyzed by unpaired $t$-test with Welch correction and a 95\% confidence interval. 


\subsection{B-Galactosidase Activity Associated with Senescence (S.A. $\beta$-Gal)}

To quantify S.A. $\beta$-gal activity, we used a previously reported chromogenic assay [111]. In brief, we fixed B16F1 cells with a $0.2 \%(\mathrm{~m} / \mathrm{v})$ paraformaldehyde solution (Merck) and $0.2 \%(v / v)$ glutaraldehyde (Sigma-Aldrich) for $10 \mathrm{~min}$ at $4{ }^{\circ} \mathrm{C}$. We incubated for $18 \mathrm{~h}$ at $37^{\circ} \mathrm{C}$ without $\mathrm{CO}_{2}$ with the substrate and chromogenic solution containing: $1 \mathrm{mg} / \mathrm{mL}$ of X-gal reagent (Invitrogen, Carlsbad, CA, USA), $61 \mathrm{mM}$ citric acid/sodium phosphate ( $\mathrm{pH} 4.0, \mathrm{pH} 6.0$ and $\mathrm{pH} 7.5$; as appropriate), $5 \mathrm{mM} \mathrm{K}_{3} \mathrm{Fe}[\mathrm{CN}]_{6}$ (Sigma-Aldrich), $5 \mathrm{mM} \mathrm{K}_{4} \mathrm{Fe}$ $\left[\mathrm{CN}_{6}\right.$ (Sigma-Aldrich), $150 \mathrm{mM} \mathrm{NaCl}$ (Merck) and $2 \mathrm{mM} \mathrm{MgCl}_{2}$ (Merck). We documented the changes through a photographic record and spectrophotometric quantification. The staining solution was removed and washed with PBS pH 7.4 at room temperature and protected from light. We dissolved the $\beta$-galactosidase product with $200 \mu \mathrm{L}$ of $99 \%$ DMSO by $5 \mathrm{~h}$ and then quantified at $600 \mathrm{~nm}$ in the Glomax spectrophotometer. Data were expressed as the average of four independent trials \pm standard deviation and analyzed by unpaired $t$-test with Welch correction and a 95\% confidence interval.

\subsection{Protein Detection by Immunofluorescence}

Cells seeded in coverslips in the presence or absence of $5 \mathrm{mM} \mathrm{L-Tyr}$ or $2.5 \mu \mathrm{g} / \mathrm{mL}$ 5 -Brd-2'-dU were fixed with $4 \%(\mathrm{~m} / \mathrm{v})$ paraformaldehyde in PBS, permeabilized with $0.3 \%$ $(v / v)$ Triton X-100 and incubated with the rabbit polyclonal primary antibody (Santa Cruz Biotechnology Inc, Dallas, TX, USA): anti-Cdk2 (sc-163), anti-Cdk4 (sc-260), anti-cyclin D1 (sc-717), anti-p21 (sc-756), anti-TRP1 (sc-25543), anti-Dct (sc-25544), anti-Tyrosinase-Tyr (sc-15341) or anti-MITF (sc-11002), the latter made in goat. To detect H3K9me3, we used a polyclonal antibody made in rabbits (ab8898) (Abcam, Cambridge, UK), in all cases, final concentration of primary antibody was $0.4 \mu \mathrm{g} / \mathrm{mL}$. As a secondary antibody, we used a CFL647-labeled goat anti-rabbit (sc-362292) (Santa Cruz), and for H3K9me3 and MITF, a CFL488-labeled goat anti-rabbit (sc-362262) and a chicken-marked anti-goat marked with Texas Red (sc-3923), respectively, both from (Santa Cruz) with concentrations and incubation times following manufacturer's recommendations $(0.4 \mu \mathrm{g} / \mathrm{mL})$. After nuclei labeled with DAPI (4',6-diamidino-2-phenylindole) (Sigma-Aldrich) and the coverslips mounted on $25 \%(v / v)$ glycerol (Merck), we acquired the images under an inverted microscope (Eclipse $\mathrm{Ti}$, Kobe, Japan) in a bright field and with the filter corresponding to the used fluorophores. We quantified the mean fluorescence intensities (MFI) and calculated the apparent cell area from the bright-field photographs after defining each cell's perimeter on the NISElements program.

\subsection{Protein Expression by Western Blot}

B16F1 cells were washed with sterile PBS and mechanically lysed in the presence of RIPA buffer (Sigma-Aldrich) containing $1 \mathrm{mM}$ phenyl-methyl sulfonyl-fluoride (PMFS) (Sigma-Aldrich) as a protease inhibitor. The samples were centrifuged at $13,000 \times g$ for $15 \mathrm{~min}$ at $4{ }^{\circ} \mathrm{C}$. The supernatant and the protein concentration were quantified using a calibration curve constructed with bovine serum albumin and bicinchoninic acid (Pierce TM BCA Protein Assay Kitt, Thermo Fisher Scientific) following the manufacturer's recommendations. A total of $30 \mu \mathrm{g}$ of protein quantified per sample was removed by $10 \%$ SDS-PAGE electrophoresis under denaturing conditions. The obtained gels were electro-transferred to a PVDF membrane (Millipore-Merck) using the Novex ${ }^{\circledR}$ semi-dry system (Thermo Fisher Scientific) following the manufacturer's recommendations. For immuno-detection, the non-specific sites of the PVDF membrane were blocked with a $1 \%(\mathrm{~m} / \mathrm{v})$ solution of polyvinylpyrrolidone (PVP-40) (Sigma-Aldrich) in PBS-Tween 20 (Sigma-Aldrich) [112] and incubated with the primary antibodies used in the immunofluorescence, in addition to p16INK4a/CDKN2A (ab108349) from Abcam and p27 (sc-528) (Santa Cruz). Subsequently, the incubation with the corresponding secondary antibody marked with horseradish peroxidase-HRP (VECTOR, Burlingame, CA, USA): anti-goat made in a horse (PI-9500) and anti-rabbit made in goat (P1-1000). As load control, we used the detection of the nuclear protein Lamina B1 (sc-6216) (Santa Cruz). Finally, the detection was completed by 
chemiluminescence using ECL-western blotting system (Amersham, Boston, MA, USA) and densitometric analysis in Fiji-ImageJ (https:/ / fiji.sc/)

\subsection{Extraction of Total RNA and Enrichment of Small RNAs}

We followed the organic phase RNA extraction as the previously described protocol [113]. In brief, B16F1 cells were lysed in the presence of TRIzol (Invitrogen) to solubilize the melanin. The lysate was collected in $1.5 \mathrm{~mL}$ Eppendorf tubes and heated for $2 \mathrm{~min}$ at $65^{\circ} \mathrm{C}$ [114]. By successive centrifugations with chloroform (Sigma-Aldrich), isopropanol (Biomedical Inc.), and 75\% ethanol (Merck), the pellet dried at room temperature for $10 \mathrm{~min}$ and was resuspended in $\mathrm{H} 2 \mathrm{O}$ DEPC (diethyl pirocarbonate, Sigma-Aldrich) for subsequent RT-qPCR assays and quantified by spectrophotometry (Nanodrop 2000, Thermo Fisher Scientific); or resuspended in transport buffer following the manufacturer's recommendations, for subsequent sequencing. To obtain enriched fractions of small RNAs $\leq 200 \mathrm{nt}$, miRVana ${ }^{\mathrm{TM}}$ miRNA Isolation Kit (Ambion, Austin, TX, USA) was used following the manufacturer's recommendations.

\subsection{Small RNAseq}

We used Illumina technology (Illumina, San Diego, CA, USA) to sequence small RNAs. Before the library's construction, evaluate the total RNA's quality and integrity on an Agilent RNA ScreenTape System (Illumina) under RNA integrity number (RIN) and TruSeq Small RNA Library Prep Kit (Illumina), following the manufacturer's recommendations. A total RNA fraction coupled to $5^{\prime}$ and $3^{\prime}$ adapters to the corresponding RT-PCR for 15 cycles. The amplification products fractionated by $6 \%$ polyacrylamide gel electrophoresis, and the amplified library region containing the fraction of miRNAs (140-150 nt), was separated, precipitated with ethanol, and quantified on nanodrop. The library was run on a HiSeq 2500 (Illumina) in a fast read-per-cycle $1 \times 50$ format (single read), averaging $1.0 \times 10^{7}$ readings per sample. The quality control and the normalization of the readings obtained using the BaseSpace ${ }^{\circledR}$ App, Small RNA v1.0 (Illumina), the sequences converted into FastQ files, and the quality of the readings was analyzed multiQC and confirmed in Galaxy by FastQC (https:/ / usegalaxy.org/). The alignments for readings obtained between 17 and $35 \mathrm{nt}$ against the reference genome for Mus musculus ( $\mathrm{mm} 9$ ) and other databases including miRBase version 21 to identify mature miRNAs (http://www.mirbase.org/) in whose case was only assigned the name of the miRNAs when we found $100 \%$ identity between the reading and the miRBase reference. We registered the data at the Gene Expression Omnibus-GEO-NCBI with the access number GSE147170 (https:/ / www.ncbi.nlm.nih.gov/ geo / query / acc.cgi?acc=GSE147170).

\subsection{Principal Components Analysis-PCA}

We assessed the PCA in R code under the "plot PCA" function. To summarize the systematic patterns of variation in the readings obtained from the sequencing in principal components, we achieved orthogonal transformation by reducing each sample at one point [115], provided separate samples by expression variation, and identified possible outliers for each sample. For the construction of the 3D PCA, we used the first three principal components.

\subsection{Differential Expression Analysis of miRNAs from Sequencing Reads}

To determine the differentially expressed miRNAs, we used the DESeq2 (Bioconductor) library in R code; a library specialized in the analysis of count data that provides methods to evaluate the differential expression using the negative binomial distribution and the shrinkage estimator for the distribution of the variance $[116,117]$. We normalized the data by calculating each factor's weight using a function that calculates its weight. With the normalized data, we proceeded to calculate the miRNAs differentially expressed using the "results" function DESeq2 considering differences in expression of those miRNAs with $p$-value adjusted correction multiple, smaller testing 5\% [117]. The miRNAs' differential 
expression values were visualized in heat maps using the "pheatmap" function in $\mathrm{R}$ code [118]; we represented the differential expression data in a grid. Each row represented a miRNA, and each column represented a sample. The squares' color and intensity represent changes (not absolute values) of the expression. For illustration purposes, unsupervised clustering using the hierarchical clustering based on the Lance-Williams algorithm was performed using the library pheatmap Raivo Kolde (2019). pheatmap: R package version 1.0.12. https: / /CRAN.R-project.org/package=pheatmap and Cluster Analysis Basics and Extensions. R package version 2.1.0. in R $[119,120]$.

\subsection{Prediction of Molecular Targets (mRNAs) of microRNAs by TargetScan Mouse}

We selected some molecular targets (mRNAs), which had a previous report of changes in their expression in models of decreased growth and differential pigmentation induced by L-Tyr or 5-Brd-2'-dU with B16F1 cells or in other cell models. By using TargetScanMouse 7.1 (http:/ / www.targetscan.org/mmu_71/), we performed the prediction of all potential miRNAs that could have that gene as a molecular target. The report generated was filtered using the list of miRNAs with differential expression obtained by DESeq2 [121].

\subsection{RT-qPCR-Stem-Loop for miRNAs and RT-PCR for mRNAs}

We selected seven miRNAs to confirm their expression by RT-qPCR stem-loop. For this, we used a stable loop-type structure (stem-loop) to provide additional length to the target cDNA, optimize its melting temperature (Tm), and improve the assay's specificity (Table S4. List of primer sets for genes and miRNAs used in RT-qPCR and RT-qPCR-stem loop). The miRNAs RT and qPCR assays were conducted with the mirVana ${ }^{\mathrm{TM}}$ microRNA Detection Kit (Thermo Fisher Scientific) following the manufacturer's recommendations. We started with 65 ng of RNA for RT, and cDNA synthesis run in a thermocycler (BIO-RAD, Hercules, CA, USA): $30 \mathrm{~min}$ at $16^{\circ} \mathrm{C}, 30 \mathrm{~min}$ at $42^{\circ} \mathrm{C}$, and $5 \mathrm{~min}$ at $85^{\circ} \mathrm{C}$. For qPCR, we used $2.5 \mu \mathrm{g}$ of cDNA in the Chromo $4^{\mathrm{TM}}$ thermal cycler (BIO-RAD) under the program: 3 min at $95^{\circ} \mathrm{C}$ and 40 cycles: $15 \mathrm{~s}$ at $95^{\circ} \mathrm{C}$ for denaturation, followed by $1 \mathrm{~min}$ at $60{ }^{\circ} \mathrm{C}$ for ringing and $1 \mathrm{~min}$ at $72{ }^{\circ} \mathrm{C}$ extensions, after 40 cycles a final extension left at $72{ }^{\circ} \mathrm{C}$ for $10 \mathrm{~min}$.

For the RT-qPCR of the mRNAs, we synthesized cDNA from $2 \mathrm{ng}$ of total RNA and $500 \mu \mathrm{g} / \mathrm{mL}$ of OligodT (Invitrogen) and Superscript II reverse transcriptase (Invitrogen); the samples were run in a thermal cycler (BIO-RAD) for $50 \mathrm{~min}$ at $42{ }^{\circ} \mathrm{C}$ and $15 \mathrm{~min}$ at $70{ }^{\circ} \mathrm{C}$. For real-time PCR (qPCR), $600 \mathrm{ng}$ of cDNA, the sense and antisense primers corresponding to each evaluated mRNA (Table S4. Primers list), and DyNAmo HS SYBR Green Kit (Thermo Fisher Scientific) were used, following the manufacturer's recommendations. The amplification in a BIO-RAD Chromo $4^{\mathrm{TM}}$ under the following conditions: $95^{\circ} \mathrm{C} 15 \mathrm{~min}$ to activate the polymerase and 36 cycles that included $10 \mathrm{~s}$ at $96^{\circ} \mathrm{C}$ to denature, $30 \mathrm{~s}$ annealing temperature according to each set of primers, and $30 \mathrm{~s}$ at $72{ }^{\circ} \mathrm{C}$ extension. We identified the respective melting curve of $55-95^{\circ} \mathrm{C}$ with data obtained from the Opticon Monitor 3 (BIO-RAD) program for both qPCRs of miRNAs and mRNAs. To quantify mRNA and miRNA Differential expression analysis with $\mathrm{qPCR}$, we use the relative expression ratio (rER) model to establish the mRNAs' miRNAs' differential expression [122]. This method adjusts the expression level according to the efficiency of each PCR run. As references, we used GAPDH for mRNAs or U6 snRNA for miRNAs.

\subsection{Construction of Co-Expression Networks for miRNAs (RC-miR)}

For the RC-miR construction, we used the previously proposed [123], all in R code. The structure of these networks began with creating a similarity matrix, followed by selecting the similarity threshold, constructing an adjacency matrix, and plotting the generated groupings. It found that the relationship between miRNAs was not linear, so the calculation of the similarity matrix of each of the expression matrices was made with the criterion of mutual information (M.I.) because M.I. is capable of detecting nonlinear correlations that are undetectable for other metrics such as the Pearson coefficient [124]. 
It was necessary to perform a discretization of the normalized expression data, and we used the "Equal Frequency" method. Finally, the values were adjusted to a correlation coefficient between [0,1] [125]. We constructed six matrices of similarity by using the M.I. coefficient as a similarity metric and the expression matrix that included the normalized counts of the Small RNA-seq for the miRNAs with differential expression found in the B16F1 cells exposed or not to L-Tyr or 5-Brd-2'-dU, expressed in blocks or by groups: over or under-expressed. We established a similarity threshold to build the adjacency matrix from which the correlation (similarity) between two miRNAs was considered significant. We selected this threshold by comparing the grouping coefficient of the obtained network $(C(\tau))$ and the expected grouping coefficient for a random network $(C o(\tau v))$, with different values of (tao) $\tau$ between 0.01 and 0.99 (Equation (1)) [123,126].

$$
*=\left\{\tau_{v}:\left|C\left(\tau_{v}\right)-\operatorname{Cr}\left(\tau_{v}\right)\right|>\left|C\left(\tau_{v+1}\right)-\operatorname{Cr}\left(\tau_{v+1}\right)\right|\right\}
$$

As the RC-miRs are non-directed networks, we generated an adjacency matrix (A), indicating which nodes were connected and composed only of ones and zeros generated following Equation (2).

$$
a_{i i}=0 \text { for all } i a_{i j}=1 \text { if }\left|{ }_{i j}\right|>a_{i j}=0 \text { in other case }
$$

We visualized the network using the igraph library in $\mathrm{R}$, and we achieved the graphs obtained representing the co-expression networks of miRNAs from multiple experiments.

\subsection{Regulation Networks and Functional Enrichment}

We used miRNet to construct regulatory network models (https://www.mirnet.ca/), an open-access web-based tool that integrates multiple statistical tools, data mining, and visualization systems miRNA-target interaction studies [127,128]. In addition to implementing a flexible interface to filter, refine, and personalize data during network creation, miRNet contains a network visualization system with the possibility of functional enrichment analysis via KEGG, G.O., and Reactome signaling pathways. Tool fed with miRNAs I.D.s over or under-expressed by exposure to L-Tyr or 5-Brd-2'-dU, and for functional enrichment, we used the KEGG signaling pathways and statistical analysis hypergeometric test.

\subsection{Statistic Analysis}

We used an unpaired Student's $t$-test to test for significant differences between each exposure and control. Except where otherwise noted, the number of independent replicates used in the statistical analyses was three; values reported as mean \pm S.D. and results were considered not significant (ns) with $p>0.05$, significant $\left({ }^{*}\right)$ with $p<0.05$, very significant $\left(^{* *}\right)$ with $p<0.01$, highly significant $\left(^{* * *}\right)$ with $p<0.001$ and very highly significant $(* * * *)$ with $p<0.0001$. For multiple tests, the significance level (a two-tailed $t$-multiple test was performed $\left.{ }^{*}\right)$, and the differences were considered statistically significant for a $p$-value $<0.05$ using the Holm-Sidak method with GraphPad Prism ${ }^{\circledR}$ (Graphpad Software Inc., La Jolla, CA, USA). The functional enrichment by KEGG signaling pathways in the miRNet web tool included hypergeometric tests and was considered statistically significant for $p<0.05$ values. Finally, the significance statistic of differentially expressed microRNAs from small RNAseq counts was carried out with DESeq2 algorithm in R code and included the correction of multiple tests.

\section{Conclusions}

L-Tyr and 5-Brd-2'-dU induces a profile of microRNAs in the melanoma cell line B16F1. We identified potential miRNA antagonism and coordination networks on genes involved in pigmentation, cell cycle control, and senescence.

Supplementary Materials: Supplementary materials can be found at https:/ / www.mdpi.com/1422 $-0067 / 22 / 4 / 1591 / s 1$. 
Author Contributions: Conceptualization, H.M.R. and L.A.G.; methodology, H.M.R. and L.A.G.; software, D.O., M.F. and M.C.; validation, H.M.R. and E.N.M.; formal analysis, H.M.R., E.N.M., D.O., M.F. and M.C.; investigation, H.M.R., E.N.M. and L.A.G.; data curation, H.M.R., D.O., M.F. and M.C.; writing-original draft preparation, H.M.R. and E.N.M.; writing-review and editing, H.M.R. and L.A.G.; visualization, H.M.R. and L.A.G.; supervision, L.A.G.; project direction, L.A.G. All authors have read and agreed to the published version of the manuscript.

Funding: This research was funded by resources from the National Institute of Health Colombia. Project-grant No. CETIN-01-2016 (to LAG). HMR is a recipient of a Doctoral Program Fellowship. The support that HMR received from COLCIENCIAS, MinCiencias and INS is acknowledged.

Institutional Review Board Statement: Not applicable for studies not involving humans or animals. Informed Consent Statement: Not applicable for studies not involving humans.

Data Availability Statement: Publicly available datasets were analyzed in this study. This data can be found here [https:/ / www.ncbi.nlm.nih.gov / geo/query / acc.cgi?acc=GSE147170].

Acknowledgments: The authors thanks the National Institute of Health Colombia (INS) and the National University of Colombia (UNAL).

Conflicts of Interest: The authors declare no conflict of interest.

\section{References}

1. Aftab, M.N.; Dinger, M.E.; Perera, R.J. The role of microRNAs and long non-coding RNAs in the pathology, diagnosis, and management of melanoma. Arch. Biochem. Biophys. 2014, 563, 60-70. [CrossRef] [PubMed]

2. Damsky, W.E.; Theodosakis, N.; Bosenberg, M. Melanoma metastasis: New concepts and evolving paradigms. Oncogene 2014, 33, 2413-2422. [CrossRef] [PubMed]

3. Haass, N.K.; Smalley, K.S.; Li, L.; Herlyn, M. Adhesion, migration and communication in melanocytes and melanoma. Pigment Cell Res. 2005, 18, 150-159. [CrossRef] [PubMed]

4. Sarkar, D.; Leung, E.Y.; Baguley, B.C.; Finlay, G.J.; Askarian-Amiri, M.E. Epigenetic regulation in human melanoma: Past and future. Epigenetics 2015, 10, 103-121. [CrossRef] [PubMed]

5. Lee, J.T. Epigenetic regulation by long noncoding RNAs. Science 2012, 338, 1435-1439. [CrossRef] [PubMed]

6. Glud, M.; Gniadecki, R. MicroRNAs in the pathogenesis of malignant melanoma. J. Eur. Acad. Dermatol. Venereol. 2013, 27, 142-150. [CrossRef] [PubMed]

7. Kunz, M. MicroRNAs in melanoma biology. Adv. Exp. Med. Biol. 2013, 774, 103-120. [CrossRef] [PubMed]

8. Mione, M.; Bosserhoff, A. MicroRNAs in melanocyte and melanoma biology. Pigment Cell Melanoma Res. 2015, $28,340-354$. [CrossRef] [PubMed]

9. Ameres, S.L.; Zamore, P.D. Diversifying microRNA sequence and function. Nat. Rev. Mol. Cell Biol. 2013, 14, 475-488. [CrossRef] [PubMed]

10. Bennett, D.C. Genetics of melanoma progression: The rise and fall of cell senescence. Pigment Cell Melanoma Res. 2015. [CrossRef] [PubMed]

11. Bennett, P.E.; Bemis, L.; Norris, D.A.; Shellman, Y.G. miR in melanoma development: miRNAs and acquired hallmarks of cancer in melanoma. Physiol. Genom. 2013, 45, 1049-1059. [CrossRef] [PubMed]

12. Pritchard, C.C.; Cheng, H.H.; Tewari, M. MicroRNA profiling: Approaches and considerations. Nat. Rev. Genet. 2012, 13, 358-369. [CrossRef] [PubMed]

13. Shain, A.H.; Yeh, I.; Kovalyshyn, I.; Sriharan, A.; Talevich, E.; Gagnon, A.; Dummer, R.; North, J.; Pincus, L.; Ruben, B.; et al. The Genetic Evolution of Melanoma from Precursor Lesions. N. Engl. J. Med. 2015, 373, 1926-1936. [CrossRef] [PubMed]

14. Gomez, L.A.; Strasberg Rieber, M.; Rieber, M. Decrease in actin gene expression in melanoma cells compared to melanocytes is partly counteracted by BrdU-induced cell adhesion and antagonized by L-tyrosine induction of terminal differentiation. Biochem. Biophys. Res. Commun. 1995, 216, 84-89. [CrossRef]

15. Rieber, M.; Rieber, M.S. Cyclin-dependent kinase 2 and cyclin A interaction with E2F are targets for tyrosine induction of B16 melanoma terminal differentiation. Cell Growth Differ. 1994, 5, 1339-1346.

16. Strasberg Rieber, M.; Rieber, M. Suppression of cyclin D1 but not cdk4 or cyclin A with induction of melanoma terminal differentiation. Biochem. Biophys. Res. Commun. 1995, 216, 422-427. [CrossRef]

17. Rieber, M.; Strasberg-Rieber, M. Induction of p53 and melanoma cell death is reciprocal with down-regulation of E2F, cyclin D1 and pRB. Int. J. Cancer 1998, 76, 757-760. [CrossRef]

18. Flórez Vargas, Ó.R.; Gomez, L.A. Expresión Diferencial de dos microRNAs Asociados con el Silenciamiento de la Ciclina D1 en Células de Melanoma B16 en Senescencia Inducida por la 5-Bromo-2-desoxiuridina.Tesis de Maestría; Universidad Nacional de Colombia: Bogotá, Colombia, 2008.

19. Silagi, S.; Bruce, S.A. Suppression of malignancy and differentiation in melanotic melanoma cells. Proc. Natl. Acad. Sci. USA 1970, 66, 72-78. [CrossRef] 
20. Guerra, L.; Bover, L.; Mordoh, J. Differentiating effect of L-tyrosine on the human melanoma cell line IIB-MEL-J. Exp. Cell Res. 1990, 188, 61-65. [CrossRef]

21. Garcia, R.I.; Werner, I.; Szabo, G. Effect of 5-bromo-2'-deoxyuridine on growth and differentiation of cultured embryonic retinal pigment cells. In Vitro 1979, 15, 779-788. [CrossRef]

22. Levkoff, L.H.; Marshall, G.P., II; Ross, H.H.; Caldeira, M.; Reynolds, B.A.; Cakiroglu, M.; Mariani, C.L.; Streit, W.J.; Laywell, E.D. Bromodeoxyuridine inhibits cancer cell proliferation in vitro and in vivo. Neoplasia 2008, 10, 804-816. [CrossRef] [PubMed]

23. Ramirez, C.A.; Gomez, L.A. Extracción y Solubilidad de la Melanina Total Producida por Células de Melanoma Murino B16 Expuestas al Aminoácido L-Tirosina; Instituto Nacional de Salud: Bogotá, Colombia, 2005.

24. Fernandes, B.; Matama, T.; Guimaraes, D.; Gomes, A.; Cavaco-Paulo, A. Fluorescent quantification of melanin. Pigment Cell Melanoma Res. 2016, 29, 707-712. [CrossRef] [PubMed]

25. Ulrich, K.; Tritsch, G.L.; Moore, G.E. Tyrosine utilization by pigmented hamster melanoma cells cultured in vitro. Int. J. Cancer 1968, 3, 446-453. [CrossRef]

26. Wrathall, J.R.; Oliver, C.; Silagi, S.; Essner, E. Suppression of pigmentation in mouse melanoma cells by 5-bromodeoxyuridine: Effects on tyrosinase activity and melanosome formation. J. Cell Biol. 1973, 57, 406-423. [CrossRef]

27. Masterson, J.C.; O'Dea, S. 5-Bromo-2-deoxyuridine activates DNA damage signalling responses and induces a senescence-like phenotype in p16-null lung cancer cells. Anticancer Drugs 2007, 18, 1053-1068. [CrossRef]

28. Suzuki, T.; Michishita, E.; Ogino, H.; Fujii, M.; Ayusawa, D. Synergistic induction of the senescence-associated genes by 5-bromodeoxyuridine and AT-binding ligands in HeLa cells. Exp. Cell Res. 2002, 276, 174-184. [CrossRef]

29. Suzuki, T.; Minagawa, S.; Michishita, E.; Ogino, H.; Fujii, M.; Mitsui, Y.; Ayusawa, D. Induction of senescence-associated genes by 5-bromodeoxyuridine in HeLa cells. Exp. Gerontol. 2001, 36, 465-474. [CrossRef]

30. Pasztor, L.M.; Hu, F. An amelanotic variant of B16 malignant melanoma. Cancer Res. 1972, 32, 1769-1774.

31. Gomez, L.A.; Strasberg Rieber, M.; Rieber, M. PCR-mediated differential display and cloning of a melanocyte gene decreased in malignant melanoma and up-regulated with sensitization to DNA damage. DNA Cell Biol. 1996, 15, 423-427. [CrossRef] [PubMed]

32. Narita, M.; Nunez, S.; Heard, E.; Narita, M.; Lin, A.W.; Hearn, S.A.; Spector, D.L.; Hannon, G.J.; Lowe, S.W. Rb-mediated heterochromatin formation and silencing of E2F target genes during cellular senescence. Cell 2003, 113, 703-716. [CrossRef]

33. Epstein, W.L.; Fukuyama, K.; Drake, T.E. Ultrastructural effects of thymidine analogs in melanosomes and virus activation in cloned hamster melanoma cells in culture. Yale J. Biol. Med. 1973, 46, 471-481.

34. Price, P.M. The effect of 5-bromodeoxyuridine on messenger RNA production in cultured cells. Biochim. Biophys. Acta 1976, 447, 304-311. [CrossRef]

35. Rieber, M.; Rieber, M.S.; Urbina, C.; Lira, R. Differential response of adherent and unanchored melanoma cells to bromodeoxyuridine evidenced by specific lectin-binding protein changes. Int. J. Cancer 1989, 43, 841-844. [CrossRef] [PubMed]

36. Mueller, D.W.; Rehli, M.; Bosserhoff, A.K. miRNA expression profiling in melanocytes and melanoma cell lines reveals miRNAs associated with formation and progression of malignant melanoma. J. Investig. Dermatol. 2009, 129, 1740-1751. [CrossRef] [PubMed]

37. Gomez, L.A. Aplicación de microarreglos de cADN para estudiar algunos determinantes moleculares de la supresión del crecimiento celular en cáncer. Biomedica 2009, 29.

38. Kato, J.; Matsushime, H.; Hiebert, S.W.; Ewen, M.E.; Sherr, C.J. Direct binding of cyclin D to the retinoblastoma gene product $(\mathrm{pRb})$ and $\mathrm{pRb}$ phosphorylation by the cyclin D-dependent kinase CDK4. Genes Dev. 1993, 7, 331-342. [CrossRef]

39. Bates, S.; Bonetta, L.; MacAllan, D.; Parry, D.; Holder, A.; Dickson, C.; Peters, G. CDK6 (PLSTIRE) and CDK4 (PSK-J3) are a distinct subset of the cyclin-dependent kinases that associate with cyclin D1. Oncogene 1994, 9, 71-79.

40. Escobar, L.M. Expresión Diferencial del gen Rock alfa e Inhibición del Crecimiento de Células de Melanoma Humano y Murino Inducido por la Genisteina y la L-Tirosina In Vitro.Tesis de Maestría; Pontificia Universidad Javeriana: Bogotá, Colombia, 2000.

41. Melnikova, V.O.; Bolshakov, S.V.; Walker, C.; Ananthaswamy, H.N. Genomic alterations in spontaneous and carcinogen-induced murine melanoma cell lines. Oncogene 2004, 23, 2347-2356. [CrossRef]

42. Shin, S.Y.; Kim, C.G.; Lim, Y.; Lee, Y.H. The ETS family transcription factor ELK-1 regulates induction of the cell cycle-regulatory gene p21(Waf1/Cip1) and the BAX gene in sodium arsenite-exposed human keratinocyte HaCaT cells. J. Biol. Chem. 2011, 286, 26860-26872. [CrossRef] [PubMed]

43. Serrano, M.; Lin, A.W.; McCurrach, M.E.; Beach, D.; Lowe, S.W. Oncogenic ras provokes premature cell senescence associated with accumulation of p53 and p16INK4a. Cell 1997, 88, 593-602. [CrossRef]

44. Charrier-Savournin, F.B.; Chateau, M.T.; Gire, V.; Sedivy, J.; Piette, J.; Dulic, V. p21-Mediated nuclear retention of cyclin B1-Cdk1 in response to genotoxic stress. Mol. Biol. Cell 2004, 15, 3965-3976. [CrossRef] [PubMed]

45. Bunz, F.; Dutriaux, A.; Lengauer, C.; Waldman, T.; Zhou, S.; Brown, J.P.; Sedivy, J.M.; Kinzler, K.W.; Vogelstein, B. Requirement for p53 and p21 to sustain G2 arrest after DNA damage. Science 1998, 282, 1497-1501. [CrossRef] [PubMed]

46. Hoffmann, I.; Draetta, G.; Karsenti, E. Activation of the phosphatase activity of human cdc25A by a cdk2-cyclin E dependent phosphorylation at the G1/S transition. EMBO J. 1994, 13, 4302-4310. [CrossRef] [PubMed]

47. Stead, E.; White, J.; Faast, R.; Conn, S.; Goldstone, S.; Rathjen, J.; Dhingra, U.; Rathjen, P.; Walker, D.; Dalton, S. Pluripotent cell division cycles are driven by ectopic Cdk2, cyclin A/E and E2F activities. Oncogene 2002, 21, 8320-8333. [CrossRef] 
48. Hirobe, T.; Ishikawa, A. L-tyrosine induces melanocyte differentiation in novel pink-eyed dilution castaneus mouse mutant showing age-related pigmentation. J. Dermatol. Sci. 2015, 80, 203-211. [CrossRef]

49. Hirobe, T.; Wakamatsu, K.; Ito, S.; Abe, H.; Kawa, Y.; Mizoguchi, M. Stimulation of the proliferation and differentiation of mouse pink-eyed dilution epidermal melanocytes by excess tyrosine in serum-free primary culture. J. Cell Physiol. 2002, 191, 162-172. [CrossRef]

50. Strasberg Rieber, M.; Welch, D.R.; Miele, M.E.; Rieber, M. p53-independent increase in p21WAF1 and reciprocal down-regulation of cyclin A and proliferating cell nuclear antigen in bromodeoxyuridine-mediated growth arrest of human melanoma cells. Cell Growth Differ. 1996, 7, 197-202.

51. Rieber, M.; Rieber, M.S. Sensitization to radiation-induced DNA damage accelerates loss of bcl-2 and increases apoptosis and autophagy. Cancer Biol. Ther. 2008, 7, 1561-1566. [CrossRef]

52. Nicetto, D.; Zaret, K.S. Role of H3K9me3 heterochromatin in cell identity establishment and maintenance. Curr. Opin. Genet. Dev. 2019, 55, 1-10. [CrossRef]

53. Yu, Y.; Schleich, K.; Yue, B.; Ji, S.; Lohneis, P.; Kemper, K.; Silvis, M.R.; Qutob, N.; van Rooijen, E.; Werner-Klein, M.; et al. Targeting the Senescence-Overriding Cooperative Activity of Structurally Unrelated H3K9 Demethylases in Melanoma. Cancer Cell 2018, 33, 322-336. [CrossRef]

54. Morasso, M.I.; Rieber, M.S.; Gil, F.; Rieber, M. Cell adhesion regulates melanoma specific differentiation and interactions with the $3^{\prime}$ region of the tyrosinase gene. Biochem. Biophys. Res. Commun. 1990, 172, 638-645. [CrossRef]

55. Slominski, A. L-tyrosine induces synthesis of melanogenesis related proteins. Life Sci. 1989, 45, 1799-1803. [CrossRef]

56. Glud, M.; Rossing, M.; Hother, C.; Holst, L.; Hastrup, N.; Nielsen, F.C.; Gniadecki, R.; Drzewiecki, K.T. Downregulation of miR-125b in metastatic cutaneous malignant melanoma. Melanoma Res. 2010, 20, 479-484. [CrossRef] [PubMed]

57. Kozubek, J.; Ma, Z.; Fleming, E.; Duggan, T.; Wu, R.; Shin, D.G.; Dadras, S.S. In-depth characterization of microRNA transcriptome in melanoma. PLoS ONE 2013, 8, e72699. [CrossRef] [PubMed]

58. Liu, S.; Tetzlaff, M.T.; Liu, A.; Liegl-Atzwanger, B.; Guo, J.; Xu, X. Loss of microRNA-205 expression is associated with melanoma progression. Lab. Investig. 2012, 92, 1084-1096. [CrossRef] [PubMed]

59. Schultz, J.; Lorenz, P.; Gross, G.; Ibrahim, S.; Kunz, M. MicroRNA let-7b targets important cell cycle molecules in malignant melanoma cells and interferes with anchorage-independent growth. Cell Res. 2008, 18, 549-557. [CrossRef] [PubMed]

60. Sand, M.; Skrygan, M.; Sand, D.; Georgas, D.; Gambichler, T.; Hahn, S.A.; Altmeyer, P.; Bechara, F.G. Comparative microarray analysis of microRNA expression profiles in primary cutaneous malignant melanoma, cutaneous malignant melanoma metastases, and benign melanocytic nevi. Cell Tissue Res. 2013, 351, 85-98. [CrossRef]

61. Diermeier, S.; Schmidt-Bruecken, E.; Kubbies, M.; Kunz-Schughart, L.A.; Brockhoff, G. Exposure to continuous bromodeoxyuridine (BrdU) differentially affects cell cycle progression of human breast and bladder cancer cell lines. Cell Prolif. 2004, 37, 195-206. [CrossRef]

62. Michishita, E.; Nakabayashi, K.; Suzuki, T.; Kaul, S.C.; Ogino, H.; Fujii, M.; Mitsui, Y.; Ayusawa, D. 5-Bromodeoxyuridine induces senescence-like phenomena in mammalian cells regardless of cell type or species. J. Biochem. 1999, 126, 1052-1059.

63. Silagi, S. Effects of 5-bromodeoxyuridine on tumorigenicity, immunogenicity, virus production, plasminogen activator, and melanogenesis of mouse melanoma cells. Int. Rev. Cytol. 1976, 45, 65-111.

64. Thomas, L.; Chan, P.W.; Chang, S.; Damsky, C. 5-Bromo-2-deoxyuridine regulates invasiveness and expression of integrins and matrix-degrading proteinases in a differentiated hamster melanoma cell. J. Cell. Sci. 1993, 105, 191-201. [PubMed]

65. Rauth, S.; Davidson, R.L. Suppression of tyrosinase gene expression by bromodeoxyuridine in Syrian hamster melanoma cells is not due to its incorporation into upstream or coding sequences of the tyrosinase gene. Somat. Cell Mol. Genet 1993, 19, 285-293. [CrossRef] [PubMed]

66. Slominski, A.; Paus, R. Are L-tyrosine and L-dopa hormone-like bioregulators? J. Theor. Biol. 1990, 143, 123-138. [CrossRef]

67. Slominski, A.; Zmijewski, M.A.; Pawelek, J. L-tyrosine and L-dihydroxyphenylalanine as hormone-like regulators of melanocyte functions. Pigment Cell Melanoma Res. 2012, 25, 14-27. [CrossRef] [PubMed]

68. Solano, F. Melanins: Skin Pigments and Much More-Types, Structural Models, Biological Functions, and Formation Routes. New J. Sci. 2014, 2014, 498276. [CrossRef]

69. Gunturiz, M.L.; Gómez, L.A. Expresión de Los Genes Que Regulan La Síntesis de Melanina: MITF-M, TRP1 y TRP2 En Células de Melanoma Maligno B16 y A375; Instituto Nacional de Salud: Bogotá, Colombia, 2013; p. 51.

70. Rauth, S.; Hoganson, G.E.; Davidson, R.L. Bromodeoxyuridine- and cyclic AMP-mediated regulation of tyrosinase in Syrian hamster melanoma cells. Somat. Cell Mol. Genet. 1990, 16, 583-592. [CrossRef]

71. Haflidadottir, B.S.; Bergsteinsdottir, K.; Praetorius, C.; Steingrimsson, E. miR-148 regulates Mitf in melanoma cells. PLoS ONE 2010, 5, e11574. [CrossRef]

72. Git, A.; Dvinge, H.; Salmon-Divon, M.; Osborne, M.; Kutter, C.; Hadfield, J.; Bertone, P.; Caldas, C. Systematic comparison of microarray profiling, real-time PCR, and next-generation sequencing technologies for measuring differential microRNA expression. RNA 2010, 16, 991-1006. [CrossRef]

73. Chen, C.; Ridzon, D.A.; Broomer, A.J.; Zhou, Z.; Lee, D.H.; Nguyen, J.T.; Barbisin, M.; Xu, N.L.; Mahuvakar, V.R.; Andersen, M.R.; et al. Real-time quantification of microRNAs by stem-loop RT-PCR. Nucleic Acids Res. 2005, 33, e179. [CrossRef]

74. Tay, Y.; Zhang, J.; Thomson, A.M.; Lim, B.; Rigoutsos, I. MicroRNAs to Nanog, Oct4 and Sox2 coding regions modulate embryonic stem cell differentiation. Nature 2008, 455, 1124-1128. [CrossRef] 
75. Li, R.; Qian, N.; Tao, K.; You, N.; Wang, X.; Dou, K. MicroRNAs involved in neoplastic transformation of liver cancer stem cells. J. Exp. Clin. Cancer Res. 2010, 29, 169. [CrossRef]

76. Tam, S.W.; Theodoras, A.M.; Shay, J.W.; Draetta, G.F.; Pagano, M. Differential expression and regulation of Cyclin D1 protein in normal and tumor human cells: Association with Cdk4 is required for Cyclin D1 function in G1 progression. Oncogene 1994, 9, 2663-2674.

77. Couts, K.L.; Anderson, E.M.; Gross, M.M.; Sullivan, K.; Ahn, N.G. Oncogenic B-Raf signaling in melanoma cells controls a network of microRNAs with combinatorial functions. Oncogene 2013, 32, 1959-1970. [CrossRef]

78. Chen, J.; Feilotter, H.E.; Pare, G.C.; Zhang, X.; Pemberton, J.G.; Garady, C.; Lai, D.; Yang, X.; Tron, V.A. MicroRNA-193b represses cell proliferation and regulates cyclin D1 in melanoma. Am. J. Pathol. 2010, 176, 2520-2529. [CrossRef] [PubMed]

79. Muller, D.W.; Bosserhoff, A.K. Integrin beta 3 expression is regulated by let-7a miRNA in malignant melanoma. Oncogene 2008, 27, 6698-6706. [CrossRef] [PubMed]

80. Zhang, Z.; Zhang, S.; Ma, P.; Jing, Y.; Peng, H.; Gao, W.-Q.; Zhuang, G. Lin28B promotes melanoma growth by mediating a microRNA regulatory circuit. Carcinogenesis 2015, 36, 937-945. [CrossRef] [PubMed]

81. Fu, T.Y.; Chang, C.C.; Lin, C.T.; Lai, C.H.; Peng, S.Y.; Ko, Y.J.; Tang, P.C. Let-7b-mediated suppression of basigin expression and metastasis in mouse melanoma cells. Exp. Cell Res. 2011, 317, 445-451. [CrossRef] [PubMed]

82. Serguienko, A.; Grad, I.; Wennerstrom, A.B.; Meza-Zepeda, L.A.; Thiede, B.; Stratford, E.W.; Myklebost, O.; Munthe, E. Metabolic reprogramming of metastatic breast cancer and melanoma by let-7a microRNA. Oncotarget 2015, 6, 2451-2465. [CrossRef]

83. Long, J.; Menggen, Q.; Wuren, Q.; Shi, Q.; Pi, X. Long Noncoding RNA Taurine-Upregulated Gene1 (TUG1) Promotes Tumor Growth and Metastasis through TUG1/Mir-129-5p/Astrocyte-Elevated Gene-1 (AEG-1) Axis in Malignant Melanoma. Med. Sci. Monit. 2018, 24, 1547-1559. [CrossRef]

84. Shen, X.; Kong, S.; Yang, Q.; Yin, Q.; Cong, H.; Wang, X.; Ju, S. PCAT-1 promotes cell growth by sponging miR-129 via MAP3K7/NF-kappaB pathway in multiple myeloma. J. Cell Mol. Med. 2020. [CrossRef]

85. Diao, Y.; Jin, B.; Huang, L.; Zhou, W. MiR-129-5p inhibits glioma cell progression in vitro and in vivo by targeting TGIF2. J. Cell Mol. Med. 2018, 22, 2357-2367. [CrossRef] [PubMed]

86. Zeng, A.; Yin, J.; Li, Y.; Li, R.; Wang, Z.; Zhou, X.; Jin, X.; Shen, F.; Yan, W.; You, Y. miR-129-5p targets Wnt5a to block PKC/ERK/NF-kappaB and JNK pathways in glioblastoma. Cell Death Dis. 2018, 9, 394. [CrossRef] [PubMed]

87. Xu, S.; Ge, J.; Zhang, Z.; Zhou, W. MiR-129 inhibits cell proliferation and metastasis by targeting ETS1 via PI3K/AKT/mTOR pathway in prostate cancer. Biomed. Pharmacother. 2017, 96, 634-641. [CrossRef] [PubMed]

88. Jiang, Z.; Zhang, Y.; Chen, X.; Wu, P.; Chen, D. Inactivation of the Wnt/beta-catenin signaling pathway underlies inhibitory role of microRNA-129-5p in epithelial-mesenchymal transition and angiogenesis of prostate cancer by targeting ZIC2. Cancer Cell Int. 2019, 19, 271. [CrossRef]

89. Ya, G.; Wang, H.; Ma, Y.; Hu, A.; Ma, Y.; Hu, J.; Yu, Y. Serum miR-129 functions as a biomarker for colorectal cancer by targeting estrogen receptor (ER) beta. Pharmazie 2017, 72, 107-112. [CrossRef]

90. Setijono, S.R.; Park, M.; Kim, G.; Kim, Y.; Cho, K.W.; Song, S.J. miR-218 and miR-129 regulate breast cancer progression by targeting Lamins. Biochem. Biophys. Res. Commun. 2018, 496, 826-833. [CrossRef]

91. Zhao, J.J.; Lin, J.; Zhu, D.; Wang, X.; Brooks, D.; Chen, M.; Chu, Z.B.; Takada, K.; Ciccarelli, B.; Admin, S.; et al. miR-30-5p functions as a tumor suppressor and novel therapeutic tool by targeting the oncogenic Wnt/beta-catenin/BCL9 pathway. Cancer Res. 2014, 74, 1801-1813. [CrossRef]

92. Ouzounova, M.; Vuong, T.; Ancey, P.B.; Ferrand, M.; Durand, G.; Le-Calvez Kelm, F.; Croce, C.; Matar, C.; Herceg, Z.; HernandezVargas, H. MicroRNA miR-30 family regulates non-attachment growth of breast cancer cells. BMC Genom. 2013, 14, 139. [CrossRef]

93. Zhang, R.; Xu, J.; Zhao, J.; Bai, J. Mir-30d suppresses cell proliferation of colon cancer cells by inhibiting cell autophagy and promoting cell apoptosis. Tumour. Biol. 2017, 39. [CrossRef]

94. Li, J.; Donath, S.; Li, Y.; Qin, D.; Prabhakar, B.S.; Li, P. miR-30 regulates mitochondrial fission through targeting p53 and the dynamin-related protein-1 pathway. PLoS Genet. 2010, 6, e1000795. [CrossRef]

95. Wu, C.; Jin, B.; Chen, L.; Zhuo, D.; Zhang, Z.; Gong, K.; Mao, Z. MiR-30d induces apoptosis and is regulated by the Akt/FOXO pathway in renal cell carcinoma. Cell Signal 2013, 25, 1212-1221. [CrossRef] [PubMed]

96. Martinez, I.; Cazalla, D.; Almstead, L.L.; Steitz, J.A.; DiMaio, D. miR-29 and miR-30 regulate B-Myb expression during cellular senescence. Proc. Natl. Acad. Sci. USA 2011, 108, 522-527. [CrossRef] [PubMed]

97. Su, W.; Hong, L.; Xu, X.; Huang, S.; Herpai, D.; Li, L.; Xu, Y.; Truong, L.; Hu, W.Y.; Wu, X.; et al. miR-30 disrupts senescence and promotes cancer by targeting both p16(INK4A) and DNA damage pathways. Oncogene 2018, 37, 5618-5632. [CrossRef] [PubMed]

98. Gaziel-Sovran, A.; Segura, M.F.; Di Micco, R.; Collins, M.K.; Hanniford, D.; Vega-Saenz de Miera, E.; Rakus, J.F.; Dankert, J.F.; Shang, S.; Kerbel, R.S.; et al. miR-30b/30d regulation of GalNAc transferases enhances invasion and immunosuppression during metastasis. Cancer Cell 2011, 20, 104-118. [CrossRef] [PubMed]

99. Rieber, M.S.; Rieber, M. Specific tyrosinases associated with melanoma replicative senescence and melanogenesis. Cancer Res. 1993, 53, 2469-2471. [PubMed]

100. Sestakova, B.; Ondrusova, L.; Vachtenheim, J. Cell cycle inhibitor p21/ WAF1/ CIP1 as a cofactor of MITF expression in melanoma cells. Pigment Cell Melanoma Res. 2010, 23, 238-251. [CrossRef] [PubMed] 
101. Du, J.; Widlund, H.R.; Horstmann, M.A.; Ramaswamy, S.; Ross, K.; Huber, W.E.; Nishimura, E.K.; Golub, T.R.; Fisher, D.E. Critical role of CDK2 for melanoma growth linked to its melanocyte-specific transcriptional regulation by MITF. Cancer Cell 2004, 6, 565-576. [CrossRef]

102. Haddad, M.M.; Xu, W.; Schwahn, D.J.; Liao, F.; Medrano, E.E. Activation of a cAMP pathway and induction of melanogenesis correlate with association of p16(INK4) and p27(KIP1) to CDKs, loss of E2F-binding activity, and premature senescence of human melanocytes. Exp. Cell Res. 1999, 253, 561-572. [CrossRef]

103. Dai, X.; Rao, C.; Li, H.; Chen, Y.; Fan, L.; Geng, H.; Li, S.; Qu, J.; Hou, L. Regulation of pigmentation by microRNAs: MITFdependent microRNA-211 targets TGF-beta receptor 2. Pigment Cell Melanoma Res. 2015, 28, 217-222. [CrossRef]

104. Vitiello, M.; Tuccoli, A.; D'Aurizio, R.; Sarti, S.; Giannecchini, L.; Lubrano, S.; Marranci, A.; Evangelista, M.; Peppicelli, S.; Ippolito, C.; et al. Context-dependent miR-204 and miR-211 affect the biological properties of amelanotic and melanotic melanoma cells. Oncotarget 2017, 8, 25395-25417. [CrossRef]

105. Noguchi, S.; Mori, T.; Otsuka, Y.; Yamada, N.; Yasui, Y.; Iwasaki, J.; Kumazaki, M.; Maruo, K.; Akao, Y. Anti-oncogenic microRNA203 induces senescence by targeting E2F3 protein in human melanoma cells. J. Biol. Chem. 2012, 287, 11769-11777. [CrossRef] [PubMed]

106. Glud, M.; Manfe, V.; Biskup, E.; Holst, L.; Dirksen, A.M.; Hastrup, N.; Nielsen, F.C.; Drzewiecki, K.T.; Gniadecki, R. MicroRNA miR-125b induces senescence in human melanoma cells. Melanoma Res. 2011, 21, 253-256. [CrossRef] [PubMed]

107. Dar, A.A.; Majid, S.; de Semir, D.; Nosrati, M.; Bezrookove, V.; Kashani-Sabet, M. miRNA-205 suppresses melanoma cell proliferation and induces senescence via regulation of E2F1 protein. J. Biol. Chem. 2011, 286, 16606-16614. [CrossRef] [PubMed]

108. Fattore, L.; Ruggiero, C.F.; Pisanu, M.E.; Liguoro, D.; Cerri, A.; Costantini, S.; Capone, F.; Acunzo, M.; Romano, G.; Nigita, G.; et al. Reprogramming miRNAs global expression orchestrates development of drug resistance in BRAF mutated melanoma. Cell Death Differ. 2019, 26, 1267-1282. [CrossRef] [PubMed]

109. Patterson, M.K. Measurement of growth and viability of cells in culture. Methods Enzymol. 1979, 11, 141-152. [CrossRef]

110. Pozarowski, P.; Darzynkiewicz, Z. Analysis of cell cycle by flow cytometry. Methods Mol. Biol. 2004, 281, 301-311. [CrossRef] [PubMed]

111. Debacq-Chainiaux, F.; Erusalimsky, J.D.; Campisi, J.; Toussaint, O. Protocols to detect senescence-associated beta-galactosidase (SA-betagal) activity, a biomarker of senescent cells in culture and in vivo. Nat. Protoc. 2009, 4, 1798-1806. [CrossRef] [PubMed]

112. Haycock, J.W. Polyvinylpyrrolidone as a blocking agent in immunochemical studies. Anal. Biochem. 1993, 208, 397-399. [CrossRef]

113. Chomczynski, P.; Sacchi, N. Single-step method of RNA isolation by acid guanidinium thiocyanate-phenol-chloroform extraction. Anal. Biochem. 1987, 162, 156-159. [CrossRef]

114. Ryu, B.; Kim, D.S.; Deluca, A.M.; Alani, R.M. Comprehensive expression profiling of tumor cell lines identifies molecular signatures of melanoma progression. PLoS ONE 2007, 2, e594. [CrossRef]

115. Jolliffe, I. Principal Component Analysis. In Wiley StatsRef: Statistics Reference Online; John Wiley \& Sons, Ltd.: Hoboken, NJ, USA, 2014. [CrossRef]

116. Anders, S.; Huber, W. Differential expression analysis for sequence count data. Genome Biol. 2010, 11, R106. [CrossRef] [PubMed]

117. Love, M.I.; Huber, W.; Anders, S. Moderated estimation of fold change and dispersion for RNA-seq data with DESeq2. Genome Biol. 2014, 15, 550. [CrossRef] [PubMed]

118. Grant, G.R.; Manduchi, E.; Stoeckert, C.J., Jr. Analysis and management of microarray gene expression data. Curr. Protoc. Mol. Biol. 2007, 77. [CrossRef] [PubMed]

119. Cormack, R.M. A Review of Classification. J. R. Stat. Soc. Ser. A 1971, 134, 321-353. [CrossRef]

120. Mächler, M.; Rousseeuw, P.; Struyf, A.; Hubert, M.; Hornik, K. Cluster: Cluster Analysis Basics and Extensions; 2012; Available online: https://cran.r-project.org/web/packages/available_packages_by_name.html (accessed on 8 April 2016).

121. Agarwal, V.; Bell, G.W.; Nam, J.W.; Bartel, D.P. Predicting effective microRNA target sites in mammalian mRNAs. Elife 2015, 4. [CrossRef] [PubMed]

122. Schefe, J.H.; Lehmann, K.E.; Buschmann, I.R.; Unger, T.; Funke-Kaiser, H. Quantitative real-time RT-PCR data analysis: Current concepts and the novel "gene expression's CT difference" formula. J. Mol. Med. 2006, 84, 901-910. [CrossRef]

123. Leal, L.G.; Lopez, C.; Lopez-Kleine, L. Construction and comparison of gene co-expression networks shows complex plant immune responses. PeerJ 2014, 2, e610. [CrossRef]

124. Numata, J.; Ebenhoh, O.; Knapp, E.W. Measuring correlations in metabolomic networks with mutual information. Genome Inform. 2008, 20, 112-122.

125. Mendes, A.D.R.M.D.A. Mutual information: A dependence measure for nonlinear time series. Econometrics 2004, $344,1-358$.

126. Henao, J.D. Coexnet: An R Package to Build CO-EXpression NETworks from Microarray Data; Version 1.8.0.; view on Bioconductor; 2019; Available online: https://rdrr.io/bioc/coexnet/ (accessed on 8 November 2020).

127. Fan, Y.; Siklenka, K.; Arora, S.K.; Ribeiro, P.; Kimmins, S.; Xia, J. miRNet-Dissecting miRNA-target interactions and functional associations through network-based visual analysis. Nucleic Acids Res. 2016, 44, W135-W141. [CrossRef]

128. Fan, Y.; Xia, J. miRNet-Functional Analysis and Visual Exploration of miRNA-Target Interactions in a Network Context. Methods Mol. Biol. 2018, 1819, 215-233. [CrossRef] [PubMed] 